\title{
Alteration of Neuronal Excitability and Short-Term Synaptic Plasticity in the Prefrontal Cortex of a Mouse Model of Mental Illness
}

\author{
Gregg W. Crabtree, ${ }^{1 \star}$ Ziyi Sun, ${ }^{1 \star}$ Mirna Kvajo, ${ }^{1 *}$ Jantine A.C. Broek, ${ }^{3}$ Karine Fénelon, ${ }^{1}$ Heather McKellar, ${ }^{2}$ Lan Xiao, ${ }^{4}$ \\ Bin Xu, ${ }^{5}$ Sabine Bahn, ${ }^{3}{ }^{\oplus}$ James M. O’Donnell, ${ }^{7}$ and Joseph A. Gogos ${ }^{1,6}$ \\ ${ }^{1}$ Department of Physiology and Cellular Biophysics, College of Physicians and Surgeons, and ${ }^{2}$ Integrated Program in Cellular, Molecular, and Biophysical \\ Studies, Columbia University, New York, New York 10032, ${ }^{3}$ Cambridge Centre for Neuropsychiatric Research, Department of Chemical Engineering and \\ Biotechnology, University of Cambridge, Cambridge CB2 1QT, United Kingdom, ${ }^{4}$ Florida State University School of Medicine, Tallahassee, Florida 32304, \\ Departments of ${ }^{5}$ Psychiatry and ${ }^{6}$ Neuroscience, Columbia University Medical Center, New York, New York 10032, and ${ }^{7}$ School of Pharmacy and \\ Pharmaceutical Sciences, University at Buffalo, State University of New York, Buffalo, New York 14214
}

Using a genetic mouse model that faithfully recapitulates a DISC1 genetic alteration strongly associated with schizophrenia and other psychiatric disorders, we examined the impact of this mutation within the prefrontal cortex. Although cortical layering, cytoarchitecture, and proteome were found to be largely unaffected, electrophysiological examination of the mPFC revealed both neuronal hyperexcitability and alterations in short-term synaptic plasticity consistent with enhanced neurotransmitter release. Increased excitability of layer II/III pyramidal neurons was accompanied by consistent reductions in voltage-activated potassium currents near the action potential threshold as well as by enhanced recruitment of inputs arising from superficial layers to layer $V$. We further observed reductions in both the paired-pulse ratios and the enhanced short-term depression of layer $\mathrm{V}$ synapses arising from superficial layers consistent with enhanced neurotransmitter release at these synapses. Recordings from layer II/III pyramidal neurons revealed action potential widening that could account for enhanced neurotransmitter release. Significantly, we found that reduced functional expression of the voltagedependent potassium channel subunit $\mathrm{K}_{\mathrm{v}} 1.1$ substantially contributes to both the excitability and short-term plasticity alterations that we observed. The underlying dysregulation of $\mathrm{K}_{\mathrm{v}} 1.1$ expression was attributable to cAMP elevations in the PFC secondary to reduced phosphodiesterase 4 activity present in Discl deficiency and was rescued by pharmacological blockade of adenylate cyclase. Our results demonstrate a potentially devastating impact of Discl deficiency on neural circuit function, partly due to $\mathrm{K}_{\mathrm{v}} 1.1$ dysregulation that leads to a dual dysfunction consisting of enhanced neuronal excitability and altered short-term synaptic plasticity.

Key words: Disc1 mouse model; excitability; $\mathrm{K}_{\mathrm{v}}$ channels; prefrontal cortex; schizophrenia; synaptic plasticity

\section{Significance Statement}

Schizophrenia is a profoundly disabling psychiatric illness with a devastating impact not only upon the afflicted but also upon their families and the broader society. Although the underlying causes of schizophrenia remain poorly understood, a growing body of studies has identified and strongly implicated various specific risk genes in schizophrenia pathogenesis. Here, using a genetic mouse model, we explored the impact of one of the most highly penetrant schizophrenia risk genes, DISC1, upon the medial prefrontal cortex, the region believed to be most prominently dysfunctional in schizophrenia. We found substantial derangements in both neuronal excitability and short-term synaptic plasticity - parameters that critically govern neural circuit information processing — suggesting that similar changes may critically, and more broadly, underlie the neural computational dysfunction prototypical of schizophrenia.

\section{Introduction}

The mechanistic details underlying the neural circuit dysfunction responsible for schizophrenia (SCZ) and other psychiatric disor- ders remain poorly understood, but there is strong support for a dominant influence of genetic variation predisposing to disease (Mitchell, 2012; Rodriguez-Murillo et al., 2012). While most 
common genetic risk variants confer only a marginally increased risk for disease, a subset of rare and ultra-rare (private) risk variants, including DISC1, is more disease penetrant, conferring high risk. DISC1 is a susceptibility gene for major mental illness that is identified through a balanced chromosomal translocation (1; 11)(q42.1;q14.3) leading to a truncation of the DISC1 gene, and segregating with SCZ, bipolar disorder, and major depression in a large Scottish pedigree. The Disc1 translocation represents one of the very few examples of ultra-rare mutations that have been strongly linked to psychiatric illness. Although more common variations in DISC1 were also associated with SCZ and affective disorders (Kvajo et al., 2010), these findings remain equivocal. The function of DISC1 has been interrogated in mouse models using a variety of approaches, such as acute RNAi-mediated gene knockdown (Duan et al., 2007) and mouse models overexpressing truncated forms of the human DISC1 (Hikida et al., 2007) and carrying missense mutations (Clapcote et al., 2007) or deletions of exons 2 and 3 (Kuroda et al., 2011). A wealth of phenomenological data has been accrued and a variety of potential Disc1-interacting proteins has been tentatively implicated in disease, but the molecular mechanisms by which DISC1 mutations predispose individuals to mental illness remain poorly understood (Bradshaw and Porteus, 2012).

Previously, we developed a disease-focused mouse model carrying a truncating lesion in the endogenous murine Discl ortholog that was designed to mimic the effects of the $(1 ; 11)$ translocation (Mouse Genome Informatics nomenclature: Disc1 ${ }^{\text {Tm1Kara }}$; Koike et al., 2006; Kvajo et al., 2008, 2011). A comprehensive behavioral analysis has shown that Disc1 ${ }^{\text {Tm1Kara }}$ mice display specific and robust impairments in working memory (Koike et al., 2006; Kvajo et al., 2008), which may relate to similar cognitive deficits that are prominent in psychotic disorders. As working memory dysfunction points to a dysfunction of prefrontal cortical neural circuits (Arguello and Gogos, 2010, 2012), we examined the cytoarchitecture, proteomic profiles, and neuronal physiology of the prefrontal cortex in Disc1 $^{\text {Tm1Kara }}$ mice (hereafter called Disc1 mutant mice).

Here we show that while cortical layering and cytoarchitecture in the prefrontal cortex (PFC) is largely normal in Disc1 mutant mice at the resolution of our assays, these mice show prominent alterations in both neuronal excitability and short-term synaptic plasticity within the medial PFC (mPFC). Specifically, we show that these mice display enhanced neuronal excitability and enhanced synaptic depression due to the increased probability of neurotransmitter release $\left(\mathrm{P}_{\mathrm{r}}\right)$. Significantly, our results provide strong support that these alterations in excitability and shortterm plasticity can both be largely attributed to reduced functional expression of the voltage-dependent potassium channel $\mathrm{K}_{\mathrm{v}} 1.1$ (KCNA1) in Disc1 mutant mice. Additionally, we provide evidence that channel dysregulation is linked to impaired phosphodiesterase function and elevated cAMP levels in the PFC of Disc1 mutant mice.

These results thus provide a novel mechanistic basis of dysfunction that may explain in part the role of Discl deficiency in neural circuit dysfunction within the prefrontal cortex and further point toward a potentially powerful disease mechanism whereby dysregulation of a single target can contribute to the

${ }^{*}$ G.W.C., Z.S., and M.K. contributed equally to this work.

The authors declare no competing financial interests.

Correspondence should be addressed to Joseph A. Gogos, Department of Physiology and Cellular Biophysics and Department of Neuroscience, Columbia University, 630 West 168th Street, New York, NY 10032. E-mail: jag90@cumc.columbia.edu.

DOI:10.1523/JNEUROSCI.4345-15.2017

Copyright $\odot 2017$ the authors $\quad 0270-6474 / 17 / 374159-23 \$ 15.00 / 0$ disruption of multiple neuronal processes, leading to neural circuit dysfunction in SCZ.

\section{Materials and Methods}

\section{Animals}

Field recordings were performed on 6- to 10-week-old male Disc1 mutant mice (Disc1 ${ }^{\text {Tm1Kara }}$ homozygotes) and their wild-type (WT) littermates. Whole-cell patch-clamp slice recordings were performed on 4- to 6-week-old male mice. All other experiments were performed on adult (8- to 10-week-old) mice, unless otherwise stated. The generation of Disc1 mutant mice has been described previously (Koike et al., 2006). The Disc1 mutation was backcrossed into the C57BL/6J background for more than six generations. All littermate mice were produced by heterozygous matings. Experiments and analyses were performed blind to the genotypes. The animal procedures were performed in accordance with and approved by the Columbia University Institutional Animal Care and Use Committee.

\section{Electrophysiology}

For field recordings in mPFC slice preparations, mice were anesthetized with isoflurane and were then decapitated. The brain was removed quickly and chilled in ice-cold dissection solution, which contained the following (in mM): 195 sucrose, $10 \mathrm{NaCl}, 2 \mathrm{NaH}_{2} \mathrm{PO}_{4}, 5 \mathrm{KCl}, 10$ glucose, $25 \mathrm{NaHCO}_{3}, 4 \mathrm{Mg}_{2} \mathrm{SO}_{4}$, and $0.5 \mathrm{CaCl}_{2}$, and was bubbled with a $95 \% \mathrm{O}_{2} /$ $5 \% \mathrm{CO}_{2}$ mixture. The coronal brain slices $(300 \mu \mathrm{m})$ containing the prelimbic and infralimbic prefrontal cortex were cut using a vibratome (VT1200S, Leica). Slices were immediately transferred to an interface chamber (models MA1 65-0075 and MA1 65-0073, Harvard Apparatus) and incubated in a recording/perfusing solution for $2 \mathrm{~h}$ before recording. The slices were continuously perfused with artificial CSF (aCSF) that contained the following composition (in $\mathrm{mM}$ ): $124 \mathrm{NaCl}, 2.5 \mathrm{KCl}, 1$ $\mathrm{NaH}_{2} \mathrm{PO}_{4}, 25 \mathrm{NaHCO}_{3}, 10$ Glucose, $1 \mathrm{MgSO}_{4}$, and $2 \mathrm{CaCl}_{2}$. The aCSF was oxygenated with $95 \% \mathrm{O}_{2} / 5 \% \mathrm{CO}_{2}$ and maintained at $\sim 34^{\circ} \mathrm{C}$. Extracellular field recordings were recorded with a borosilicate glass pipette (3-5 M $\Omega$; 1B150F-4, World Precision Instruments) filled with aCSF and field EPSPs (fEPSPs) were evoked by a concentric bipolar stimulation electrode (tip outer diameter, $0.125 \mathrm{~mm}$; CBARC75, Fine Science Tools). To record the fEPSP in layer V pyramidal neurons, a stimulating electrode was placed at the border of layer I/II and layer III in the MPFC, and the recording electrode was positioned sequentially at the layer $\mathrm{V}$. A set of stimulation intensities (from 1 to $24 \mathrm{~V}$ with a pulse duration of $0.1 \mathrm{~ms}$ ) was applied to induce the fEPSPs. The stimulation intensity, which generated a slope of $\sim 1$, was used for the all the tests. The paired-pulse ratio (PPR) was measured by applying two single stimuli with different interpulse intervals of 20, 50, 100, 200, 400, and $800 \mathrm{~ms}$. Short-term depression (STD) was assessed by using a 40-pulse train at 5, 10, 20, 40, and 50 Hz. After obtaining a stable $10 \mathrm{~min}$ baseline, short-term potentiation (STP) was evoked by a single $50 \mathrm{~Hz}$ train (40 pulses) and was monitored for $15 \mathrm{~min}$. Then, an additional four $50 \mathrm{~Hz}$ trains were applied with intervals of $10 \mathrm{~s}$, and then long-term potentiation (LTP) were recorded for $40 \mathrm{~min}$. Dendrotoxin-K (DTX-K; $\sigma$ ) was reconstituted in deionized water to yield a $10 \mu \mathrm{M}$ stock and was diluted with aCSF to prepare a 100 nM working solution. Electrophysiological signals were acquired using an extracellular amplifier (Cygnus Technologies) and pClamp software version 9 (Molecular Devices). Statistical analyses were performed using SigmaPlot 9.0 and GraphPad Prism 4. A two-way repeated-measures (RM) ANOVA was used to test genotypic differences. Data are presented as the mean \pm SEM. $N$ indicates the number of animals, and $n$ indicates the number of slices. Asterisks indicate significant differences.

For whole-cell recordings, after slicing (as described for field recordings, above), brain slices were immediately transferred to a recovery chamber and incubated at room temperature in recording solution for a minimum of $1 \mathrm{~h}$ before recording. At the time of recording, slices were transferred to a submerged recording chamber and continuously perfused with aCSF. Whole-cell patch-clamp recordings were made using borosilicate glass pipettes (initial resistance, 3.0-5.5 M ). An internal solution was used that contained the following (in mM): $\mathrm{KMeSO}_{4} 145$, HEPES 10, $\mathrm{NaCl} 10, \mathrm{CaCl}_{2} 1, \mathrm{MgCl}_{2} 1$, EGTA 10, MgATP 5, and $\mathrm{Na}_{2} \mathrm{GTP}$ 0.5 , pH 7.2 with $\mathrm{KOH}$, adjusted to $290 \mathrm{mOsm}$ with sucrose. Layer II-III 
pyramidal neurons were identified by morphology, and only neurons exhibiting spike frequency accommodation within action potential (AP) trains were included in analysis (Madison and Nicoll, 1984). Input resistance was calculated in voltage-clamp mode at $-70 \mathrm{mV}$ from the current response to a $5 \mathrm{mV}$ hyperpolarizing voltage step. For recordings assessing neuronal excitability, action potential firing was assessed in currentclamp mode in response to incremental (20 pA steps in slice, $10 \mathrm{pA}$ steps in cultured neurons) depolarizing current injections of $500 \mathrm{~ms}$ duration. The resting membrane potential of all cells was adjusted to $-70 \mathrm{mV}$ by the injection of a small standing current. For excitability assays involving DTX-K application, due to modest rundown of excitability over time, current-step protocols were first repeated at 5 min intervals until excitability stabilized at an approximate steady-state level. Thereafter, the current-step protocol was used to assess basal excitability, and then DTX-K was introduced for 5 min after which excitability in DTX-K was assessed. Action potential waveform analysis was performed on a single action potential elicited with a minimal threshold current injection. Waveform analysis used standard Clampfit analysis routines as follows: "half-width," the action potential width at half-height, was reported as AP width; "rise slope," the slope during the 10-90\% event rise time, was reported as rise rate; and "decay slope," the slope during the 10-90\% event decay time, was reported as the decay rate. For recordings assessing voltage-gated channel activation in response to voltage steps, series resistance-related errors were partially corrected by typically using $70 \%$ prediction and $85 \%$ series resistance compensation with the MultiClamp software. Voltage-gated sodium channel currents are reported as peak currents during a given voltage step. Voltage-gated potassium channel currents are reported as the quasi steady-state currents at the end of a 100 ms voltage step (Li et al., 2011). Spontaneous synaptic transmission at layer $\mathrm{V}$ pyramidal neurons was assessed with whole-cell voltage-clamp recordings. Spontaneous EPSCs (sEPSCs) were detected over 5 min recording periods with cells held in voltage clamp at $-70 \mathrm{mV}$. Spontaneous synaptic currents were analyzed using Minianalysis 6.0 software (Synaptosoft). The detection threshold for spontaneous events was $4 \mathrm{pA}$. All events were individually detected and verified manually. To test for differences in excitability between genotypes a two-way RM ANOVA was used using SigmaPlot 12. For all other comparisons between genotypes, a Student's $t$ test (unpaired, one tailed, or two tailed) was performed using Excel.

\section{Analysis of layer $V$ pyramidal neurons basal and apical spines}

The density of spines on layer $\mathrm{V}$ pyramidal cell dendrites was assessed using male adult (8-12 weeks of age) Thy-1/GFP mice crossed with Disc1 mutant mice, as previously described (Lai et al., 2006; Kvajo et al., 2008). Confocal images of basal and apical dendritic trees were captured using the Zeiss LSM Confocal Microscope, and the numbers of spines within $50 \mu \mathrm{m}$ a dendritic segment were counted.

\section{Analysis of axonal projections in embryonal day 18.5 embryos}

Brains from embryonal day 18.5 (E18.5) embryos from all three genotypes, generated by heterozygous crossings of Discl mutant mice, were dissected out and fixed overnight in $4 \%$ PFA at $4^{\circ} \mathrm{C}$. Sixty micrometer coronal sections were cut on a vibratome and stained with the mouse monoclonal anti-neurofilament antibody 2H3 (1:50; Developmental Studies Hybridoma Bank) and a rabbit polyclonal anti-L1 antibody (1: $100 ;$ Abcam) o/n at $4^{\circ} \mathrm{C}$. The sections were then washed and incubated with Alexa Fluor-conjugated secondary antibodies for $2 \mathrm{~h}$ at room temperature. After washing, the sections were labeled with the nuclear stain Topro (1:2500; Invitrogen) and mounted with ProLong Gold. For analysis, $10 \times$ images were captured using the Zeiss LSM Confocal Microscope and loaded onto the Zeiss LSM Image Browser (Zeiss), which was used to quantify the spread of axonal projections in cortical layers. To this aim, the width of the area occupied by L1- or neurofilament-labeled axons was measured along a line perpendicular to the pial surface and expressed as a fraction of the width of the whole cortex. Four WT, three heterzygous (HET), and three homoygous (HOM) embryos were used for analysis. Five to nine sections/embryo were analyzed.

\section{BrdU labeling and analysis of cortical layers}

Timed pregnant female mice were injected with bromodeoxyuridine (BrdU; $50 \mathrm{mg} / \mathrm{kg}$, i.p.) at E14.5. At postnatal day 2 (P2), brains were dissected out, fixed in $4 \%$ PFA overnight, and cut on the vibratome into $60 \mu \mathrm{m}$ slices. Sections were stained for BrdU and cortical layer markers using the following antibodies: rabbit anti-Cux1 (1:50; Santa Cruz Biotechnology); goat anti-Tbrl (1:50; Santa Cruz Biotechnology); and mouse anti-BrdU (1:200; BD Pharmingen,) according to standard procedures. For quantification, images of the whole cortex were captured using a confocal microscope (model LSM510, Zeiss) at 10×. Sections chosen for analysis were anatomically matched, and regions of interest (ROIs) encompassing all cortical layers were positioned over the cortex. The ROIs were then divided into 10 equally sized bins, and the number of BrdU-positive cells in each bin was counted. The total number of labeled cells in each ROI was also assessed. The thickness of cortical layers was assessed by measuring the width of Cux1-labeled (layers II and III) and Tbr1-labeled (layer VI) areas. To examine overall neuronal numbers in the adult cortex, anti-NeuN labeling (1:100; Millipore Bioscience Research Reagents) was used. ROIs divided into eight equal bins were drawn across a single optical section $(1 \mu \mathrm{m})$ acquired with the confocal microscope. The number of cells within the bins and within the whole ROI was quantified.

\section{Immunoblotting}

To determine phosphodiesterase 4A (PDE4A), PDE4B, or PDE4D, PFC (four mice/genotype) was homogenized in ice-cold lysis buffer (Millipore) and centrifuged at $10,000 \times g$ for $30 \mathrm{~min}$ at $4^{\circ} \mathrm{C}$. Solubilized samples were mixed with equal volumes of Laemmli sample buffer and heated to $100^{\circ} \mathrm{C}$ for $2 \mathrm{~min}$. Equal amounts of sample protein were loaded onto gels for SDS-PAGE. After separation by electrophoresis, proteins in the gels were transferred to nitrocellulose membranes, which were incubated overnight at $4^{\circ} \mathrm{C}$ with primary antibodies against PDE4A, PDE4B, or PDE4D (FabGennix). This process was followed by incubation with Alexa Fluor 680-conjugated secondary antibody for 30 min at room temperature (Invitrogen). An Odyssey Infrared Imaging System (LI-COR Biosciences) was used for quantifying fluorescence.

\section{Proteomic analysis}

Experiments were performed with 3- to 5-month-old male littermates.

Sample preparation. All biochemicals and reagents were obtained from Sigma-Aldrich, unless specified otherwise, and sample preparation was performed as previously described (Ernst et al., 2012). Protein extraction of brain tissue $(\sim 30 \mathrm{mg})$ was performed by the addition of fractionation buffer [7 M urea, 2 м thiourea, 4\% 3-[(3-cholamidopropyl) dimethylammonio]-1-propanesulfonate, 2\% ASB14, and $70 \mathrm{~mm}$ dithiotreitol (DTT)], followed by sonication for $10 \mathrm{~s}$ using a Branson Sonifier 150 (Thistle Scientific) and vortexing for $30 \mathrm{~min}$ at $4^{\circ} \mathrm{C}$ (Martins-deSouza et al., 2007). The homogenates were centrifuged for $3 \mathrm{~min}$ at $17,000 \times g$, and the supernatants were collected for precipitation of the proteins using 4:1 volumes of ice-cold acetone. The resulting pellets were suspended in $100 \mu \mathrm{l}$ of $50 \mathrm{~mm} \mathrm{NH}_{4} \mathrm{HCO}_{3}, \mathrm{pH}$ 8.0. Disulfide bonds were broken by incubation with $100 \mathrm{~mm}$ DTT for $30 \mathrm{~min}$ at $60^{\circ} \mathrm{C}$ and alkylated with $200 \mathrm{~mm}$ iodacetamide for $30 \mathrm{~min}$ at $37^{\circ} \mathrm{C}$. Proteins were cleaved into peptides by incubation with 1:50 (trypsin/protein) porcine trypsin (Promega) for $17 \mathrm{~h}$ at $37^{\circ} \mathrm{C}$ and stopped after $16 \mathrm{~h}$ by the addition of $0.80 \mu \mathrm{l}$ of $8.8 \mathrm{M} \mathrm{HCl}$. Samples were stored at $-80^{\circ} \mathrm{C}$. Before mass spectrometry (MS) analyses, $0.1 \%$ formic acid was added to a final concentration of $0.12 \mu \mathrm{g} / \mu \mathrm{l}$ protein.

Proteomic discovery using label-free liquid chromatography-MSE profiling. Quality control (QC) samples were generated using equal aliquots of all samples for use in assessing mass spectrometry performance. The samples and QCs $(0.6 \mu \mathrm{g}$ of protein) were analyzed in duplicate using a nano-ultraperformance liquid chromatography (LC) system (10 kpsi nanoAcquity, Waters). The LC comprised a $0.18 \times 20 \mathrm{~mm}$ C18 trapping column $(5 \mu \mathrm{m}$ particle size $)$ and a $0.075 \times 200 \mathrm{~mm} \mathrm{C18}$ analytical $\mathrm{BEH}$ nanocolumn (17 $\mu \mathrm{m}$ particle size). The separation buffers were $\mathrm{H}_{2} \mathrm{O}$ plus $0.1 \%$ formic acid (buffer A) and acetonitrile plus $0.1 \%$ formic acid (buffer B). Samples were desalted for 2 min with $100 \%$ buffer A, which was followed by a two-step gradient at a flow rate of $300 \mathrm{nl} / \mathrm{min}$ over $133 \mathrm{~min}$. 
The LC analytical column was coupled on-line to a $7 \mathrm{~cm}$ nanoESI emitter (10 $\mu \mathrm{m}$ tip; New Objective) on a quadrupole time-of-flight Premier mass spectrometer (Waters), and data were acquired in alternate scanning data-independent acquisition mode $\left(\mathrm{MS}^{\mathrm{E}}\right)$. During each run, 500 $\mathrm{fmol} / \mu \mathrm{l}$ glu-fibrinopeptide B was infused every $30 \mathrm{~s}$ using the LockSpray to maintain mass accuracy. The mass spectrometer was operated in $\mathrm{V}$ mode, and analyses were performed using positive nanoESI ion mode. Low-collision energy (MS) generated information about intact precursor ions $(5 \mathrm{eV})$, while high-collision energy $\left(\mathrm{MS}^{\mathrm{E}}\right)$ provides information about the peptide fragments (ramped from 17 to $40 \mathrm{eV}$ ). The cycling time of the low and high energy was $0.6 \mathrm{~s}$, and the mass range was 50-1990 Da.

Proteomic validation using label-based selected reaction monitoring mass spectrometry. Candidate proteins for the targeted label-based selected reaction monitoring MS (SRM-MS) study were chosen from in silico pathway analyses based on the LC-MS ${ }^{\mathrm{E}}$ results and from proteins found to be interacting with DISC1 in the literature. These candidate proteins were validated and quantified using SRM-MS on a Xevo TQ-S mass spectrometer coupled to a nanoAcquity UPLC system (Waters), as described previously (Martins-de-Souza et al., 2012). Criteria for selecting tryptic peptides were based on peptide count, uniqueness, and quality of transitions. Two peptides were selected for each target protein, and isotopically labeled peptides were synthesized at JPT Peptide Technologies. The samples and labeled peptides were mixed together and separated using the following 42 min gradient: $97 \% / 3 \%$ (buffer A/buffer B) to $70 \% / 30 \%$ in $20 \mathrm{~min} ; 70 \% / 30 \%$ to $15 \% / 85 \%$ in $5 \mathrm{~min}$; and in $3 \mathrm{~min}$ to $97 \% / 3 \%$. Peptide spectra were acquired in SRM mode using a capillary voltage of $2.35 \mathrm{kV}$ and a cone voltage of $33 \mathrm{~V}$. At least three transitions were measured for each peptide. The candidate proteins were validated and quantified with the SRM method, as described previously (Martinsde-Souza et al., 2012).

Data analysis. LC-MS ${ }^{\mathrm{E}}$ data were processed using the ProteinLynx Global Server version 2.5 (Waters) and Rosetta Elucidator version 3.3 (Rosetta Biosoftware) for time and mass/charge alignment of mass spectrometer data as described previously (Krishnamurthy et al., 2013). The Mus musculus complete proteome FASTA sequence Integr8 database was used for the assignment of protein identities. Quantitative peptide measurements for each replicate were normalized against the total ion volume of all deconvoluted spectra. The criteria for protein identification were set to three or more fragment ions per peptide, seven or more fragment ions per protein, and two or more peptides per protein. The data were also searched against a randomized decoy database, which was created using the original database, thus conserving amino acid frequencies. Only peptides that were present in all samples of each treatment group were considered for further analysis. The final part of the data processing was a principal component analysis (SIMCA P+ version 2.12, Umetrics), which was used to identify unwanted variability due to sample nonhomogeneity or inconsistent manipulation during the preparation and analytical stages. Testing for outlying samples resulted in removal of one frontal cortex sample. Data from this sample were not included in any further analyses. Subsequently, the LC-MS ${ }^{\mathrm{E}}$ data were analyzed in the $\mathrm{R}$ statistical programming language (version 2.15.3; $\mathrm{R}$ Development Core Team, 2013) using the MSstats package (Purdue University, West Lafayette, IN), which provides wrapper functions to simplify the fitting of linear mixed-effects models. The data of the identified proteins were $\log _{2}$ transformed to stabilize the variance and normalized to remove systematic bias incorporated into peptide intensities as a result of sample processing, which makes the peptide intensities comparable across runs. For this label-free experiment, constant normalization was performed based on endogenous signals across runs among all proteins. As proposed by Surinova et al. (2013), "inaccurate" peptide transitions were excluded based upon a between-run interference score of $<0.8$, where the score is the correlation between the individual peptide transition intensities across the runs and the mean transition intensities of the peptide across the runs (Surinova et al., 2013). Visualization of the processed data occurred using profile plots, QC plots, and condition plots provided by MSstats. Profile plots are capable of identifying the potential source of variation of each protein. The exploratory QC plots can reveal any systematic sample run variation of transition intensities between the runs, which were shown as box plots. The condition plots show the systematic difference between conditions. Analysis was performed using linear mixed models to detect differentially abundant proteins between groups, as this approach can handle the hierarchical structure of the data. The interference for biological replicates and technical replicates were used in expanded scope, which expands the conclusion from the model to the population of biological units (Chang et al., 2012). To test the model assumptions, diagnostic plots, such as residual plots to check the assumption of a constant variance, were generated, and normal quantilequantile plots to indicate whether the errors were well approximated by a normal distribution. We considered significant results when proteins were found to be changed with a significance of $p<0.05$. We used an uncorrected $p$ value threshold for significance in the discovery study because the number of mice in each group was not sufficient to reach significance after applying multiple testing corrections. We report corrected $p$ values for the discovery and validation studies following the Benjamini-Hochberg correction (Benjamini and Hochberg, 1995; Storey, 2003).

\section{Phosphodiesterase activity assay}

The PDE activity assay was performed on dissected PFC, as described previously (Zhang et al., 2008). Samples were assayed in the presence or absence of $10 \mu \mathrm{M}$ rolipram (ROL). PDE4 activity (i.e., rolipram sensitivity) was calculated by subtracting cAMP hydrolysis in the presence of rolipram from cAMP hydrolysis in its absence; four mice/genotype were used.

\section{Radioligand-binding assays}

$\left[{ }^{3} \mathrm{H}\right]$ rolipram binding was measured as described previously (Zhao et al., 2003). PFC lysate samples containing $200 \mu \mathrm{g}$ of protein were incubated at $30^{\circ} \mathrm{C}$ in the presence of $250 \mu$ l of incubation buffer that contains different concentrations of $[3 \mathrm{H}]$ rolipram $(2-30 \mathrm{~nm})$. Nonspecific binding was determined in the presence of $10 \mathrm{~nm}$ unlabeled 4-(3-butoxy-4methoxybenzyl)-2-imidazolidinone (Ro 20-1724) for $\left[{ }^{3} \mathrm{H}\right]$ rolipram binding. Reactions were stopped by the addition of $5 \mathrm{ml}$ of ice-cold binding buffer after $1 \mathrm{~h}$ and were followed by rapid vacuum filtration through glass fiber filters. The filters were washed two times, and radioactivity was measured by liquid scintillation counting.

\section{$R T$-qPCR of PDE4b expression}

For the quantification of PDE4b expression, total RNA was isolated from the PFC with TRIzol reagent (Invitrogen) according to the instructions of the manufacturer and was followed by DNase treatment to eliminate contaminated genomic DNA. The conversion of total RNA into cDNA was performed using the High-Capacity cDNA Archive Kit (Applied Biosystems). Real-time PCR was performed on an ABI PRISM 7300 Detection System (Applied Biosystems) with TaqMan Universal Mastermix (Applied Biosystems). The PDE4B primer was purchased from Applied Biosystems. The samples were run in triplicate and amplified for 40 cycles $\left(50^{\circ} \mathrm{C}\right.$ for $2 \mathrm{~min}, 90^{\circ} \mathrm{C}$ for $10 \mathrm{~min}, 95^{\circ} \mathrm{C}$ for $15 \mathrm{~s}$, and extension $60^{\circ} \mathrm{C}$ for 1 $\mathrm{min}) . \beta$-Actin was used as an endogenous control. The fold difference in the expression of target cDNA was determined using the comparative threshold method, as previously described (Zhao et al., 2003). Statistical analysis was performed using one-way ANOVA followed by Dunnett's test; three mice per genotype were used.

\section{cAMP immunohistochemistry}

cAMP immunohistochemistry and quantification were performed essentially as described previously (Kvajo et al., 2011). PFC sections were incubated with the anti-cAMP antibody (1:1000; Millipore Bioscience Research Reagents). Cortical layers were visualized using NeuN labeling (1:1000; Millipore Bioscience Research Reagents). For quantification, mPFC images were captured using a confocal microscope (LSM510, Zeiss) at $20 \times$. Sections chosen for analysis were anatomically matched, and ROIs encompassing all cortical layers were positioned over the cortex. The ROIs were then divided into 10 equally sized bins, and the intensity of cAMP immunoreactivity was quantified in each bin using ImageJ (National Institutes of Health), as previously described (Kvajo et al., 2011). 
Real-time quantitative real-time PCR analysis

PFCs were dissected out as described and placed o/n in RNAlater (Ambion). RNA was then isolated using RNeasy (Qiagen). Approximately $2 \mu \mathrm{g}$ of total RNA was reverse transcribed into double-stranded cDNA and then diluted 1:10 in double-distilled $\mathrm{H}_{2} \mathrm{O}$. Expression levels were assessed by TaqMan Gene Expression Assays: KCNA1 (Mm00439977_s1), KCNA2 (Mm00434 584_s1), KCNA3 (Mm00434599_s1), KCNA6 (Mm00496625_s1), KCNB1 (Mm00492791_m1), and SCNA8 (Mm00488110_m1; Applied Biosystems). Expression of TaqMan mouse GAPDH probe was used for normalization. Quantitative real-time PCR (qRT-PCR) was run as a $14 \mu$ reaction of $7 \mu \mathrm{l}$ of $2 \times$ TaqMan Universal Master Mix (Applied Biosystems), $0.25 \mu \mathrm{l}$ of GAPDH probe, $0.5-2 \mu$ l of probe of interest, and $1.6 \mu \mathrm{lof}$ cDNA using five technical repeats per cDNA sample on an ABI 7900HT Real-Time PCR System (Applied Biosystems). Pooled cDNA was used to generate a dilution series run in duplicate on each plate for expression quantification. Cycle thresholds were determined using SDS 2.3 software (Applied Biosystems). Expression data were calculated using median values for $\mathrm{ddCt}$ and standard curve formulas (www.AppliedBiosystems.com) and were normalized to the average of WT values.

\section{Primary cortical culture and drug treatments}

Primary cultures were prepared as described previously (Kvajo et al., 2011). Heterozygous mutant mice were crossed, resulting in embryos of all three genotypes. E15.5 telencephalic neurons were dissociated by individually dissecting each embryo out of its amniotic sac, removing the head, and dissecting out the target brain tissue in a separate dish. The remainder of the brain was used for genotyping. Neurons from each embryo were dissociated enzymatically ( $0.25 \%$ trypsin), mechanically triturated with a flamed Pasteur pipette, and individually plated on 35 $\mathrm{mm}$ dishes $(4 \times 105$ cells/dish $)$ coated with poly-DL-ornithine (SigmaAldrich) in DMEM (Invitrogen) supplemented with 10\% fetal bovine serum. Four hours after plating, DMEM was replaced by Neurobasal medium (Invitrogen) supplemented with $2 \mathrm{~mm}$ glutamine and 2\% B27 (Invitrogen). The adenylyl cyclase inhibitor SQ22536 (SQ; Tocris Bioscience) was added $13 \mathrm{~d}$ in vitro (DIV13) to a final concentration of $10 \mu \mathrm{M}$, and was replenished every $24 \mathrm{~h}$ for $4 \mathrm{~d}$ until the day of recording at DIV17/18. The PDE4 inhibitor rolipram (Tocris Bioscience) was added at DIV13 to the final concentration of $100 \mu \mathrm{M}$ and was replenished every $24 \mathrm{~h}$ for $4 \mathrm{~d}$ until the day of recording at DIV17/18. The extracellular solution for all cultured neuronal experiments was as follows (in $\mathrm{mm}$ ): $\mathrm{NaCl} 145, \mathrm{KCl} 5$, HEPES 10, $\mathrm{CaCl}_{2} 2, \mathrm{MgCl}_{2} 1$, glucose 5, and sucrose 10, pH 7.4, with osmolarity $\sim 320 \mathrm{mOsm}$.

\section{Calcium imaging of cultured cortical neurons}

Coverslips containing neurons were incubated with $5 \mu \mathrm{M}$ fura-2 AM (Life Sciences) for $30 \mathrm{~min}$ at room temperature. After washing, coverslips were mounted on a Nikon Eclipse TE 3500 inverted microscope equipped with a $40 \times 1.30$ numerical aperture objective (Nikon), a pco.EDGE CMOS camera (pco), a Lambda LS light source, a Lambda LS-2 filter wheel with 340 and $380 \mathrm{~nm}$ excitation filters (Sutter), and an $510 \mathrm{~nm}$ emission filter. Images at each excitation wavelength were acquired at $\sim 1 \mathrm{~Hz}$. Cells were perfused with extracellular solution at a high flow rate of $\sim 20 \mathrm{ml} / \mathrm{min}$.

Drug challenge applications proceeded as follows: cells were initially perfused in extracellular solution containing normal $\mathrm{Ca}^{2+}(2 \mathrm{mM})$ during which time baseline $\mathrm{Ca}^{2+}$ levels (resting 340:380 ratio) were assessed. One minute later, the perfusate was switched to a $\mathrm{Ca}^{2+}$-free extracellular solution supplemented with $4 \mathrm{~mm}$ EGTA. One minute later, the perfusate was switched to caffeine $(10 \mathrm{~mm}, 30 \mathrm{~s})$ or ATP $(100 \mu \mathrm{M}, 1 \mathrm{~min})$ in this $\mathrm{Ca}^{2+}$-free extracellular solution. The perfusate was then returned to $\mathrm{Ca}^{2+}$-free solution for $1 \mathrm{~min}$, after which it was then returned to a normal $\left(2 \mathrm{mM} \mathrm{Ca}^{2+}\right.$ ) extracellular solution for $1 \mathrm{~min}$. The perfusate was then switched to a high-potassium ( $\mathrm{HiK} ; 50 \mathrm{~mm} \mathrm{KCl}, 15 \mathrm{~s}$ ) extracellular solution containing $2 \mathrm{mM} \mathrm{Ca}^{2+}$, after which the perfusate was returned to a normal extracellular solution for $1 \mathrm{~min}$, ending the experimental run. The $\mathrm{Ca}^{2+}$ increases $(\Delta 340: 380)$ from these challenges were quantified based upon the peak responses during challenges.
Data acquisition and processing following image acquisition.

The 340:380 ratio of each pair of images was calculated on a pixel-bypixel basis using FIJI software version 1.4 (www.fiji.sc). Regions of interests were drawn manually using the morphology of the cells from a differential interference contrast image as a template. Further quantification was performed using custom routines written in Igor Pro version 6 (WaveMetrics). Only cells with robust responses to HiK challenges (presumptive neurons, $\Delta 340: 380>0.2$ ) were included in subsequent analysis. For $\mathrm{Ca}^{2+}$ store assessments, only cells with responses to caffeine or ATP challenges with $\Delta 340: 380>0.025$ were included in analyses. All individual responses were additionally qualitatively inspected manually to ensure that analysis was confined to legitimate responses as opposed to artifactual responses, which were excluded from analysis. Data were pooled across experimental runs performed on three independent embryonic dissection preparations, and two experimental trials for each assay were performed on each preparation for each genotype. Final quantitative data and statistical analysis was performed in Excel.

\section{Statistical analysis}

The individual statistical analyses used for the different experiments are stated in the respective sections in Materials and Methods or in the main text or figure legends where results are declared. In general, no formal statistical methods were used to predetermine sample sizes, but our sample sizes are similar to those generally used in the field in prior published studies. Data distributions were assumed to be normal, but this was not formally tested, although model assumptions were tested. For comparison involving repeated-measures, two-way ANOVA, repeated-measures analyses were used. For all other simple comparisons, one-way ANOVA or $t$ tests were used. When $t$ tests were used they were unpaired, two-sided except in cases in which there was a directional hypothesis in which case one-sided $t$ tests were used. Corrections for multiple comparisons were included in the statistical analysis of our results. Statistical analysis was performed in R (version 2.15.3; R Development Core Team, 2013), Microsoft Excel, SigmaPlot 11.0, and Prism 4.

\section{Results}

\section{Cortical layer formation and cytoarchitecture in Disc1 mutant mice}

We undertook a detailed histological examination of the cerebral cortices in Disc1 mutant mice. We first examined the number of neurons in the cortex of adult mice using an antibody against $\mathrm{NeuN}$, which reliably labels the majority of neuronal populations and provides a well established measure of neuronal density (Fénelon et al., 2011). We observed no difference in the numbers of labeled neurons among the genotypes (Fig. $1 A-C ; p=0.93$ ). Our earlier analysis in the hippocampus (Kvajo et al., 2011) revealed that Disc1 mutant mice displayed early postnatal alterations that were attenuated with age. Thus, we further investigated whether embryonic neurogenesis and early postnatal formation of cortical layers may be disrupted in Disc1 mutant mice. To this end, BrdU was injected into pregnant dams at E14.5, and embryonic brains were collected at P2 and P22 to analyze neural progenitor proliferation and their distribution within cortical layers. No differences in the number or distribution of BrdU-positive cells were observed at either time point (Fig. $1 D-F ; p=1.06$ ). Moreover, analysis of cortical layers, labeled with layer-specific markers Cux1 (labeling layers II-III) and Tbr1 (labeling layer VI), showed no difference in thickness at P2 (Fig. 1G,H; Cux1, $p=0.50$; Tbr1, $p=0.95)$. These data indicate that neural progenitor proliferation, neuronal migration, and cortical morphology are substantially preserved in the PFC of Disc1 mutant mice.

We next inspected axonal projections in the cortex of Disc1 mutant mice. In the developing hippocampus, we have previously observed mislocalization of terminals synapsing onto CA3 pyramidal cells in mutant mice (Kvajo et al., 2011). Immunohistochemistry against Neurofilament and L1, two markers of ax- 
A
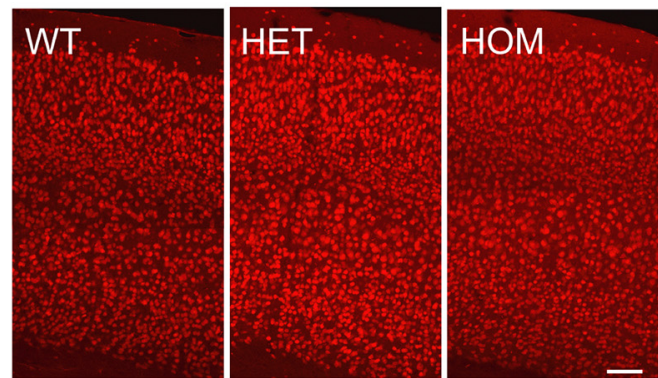

D
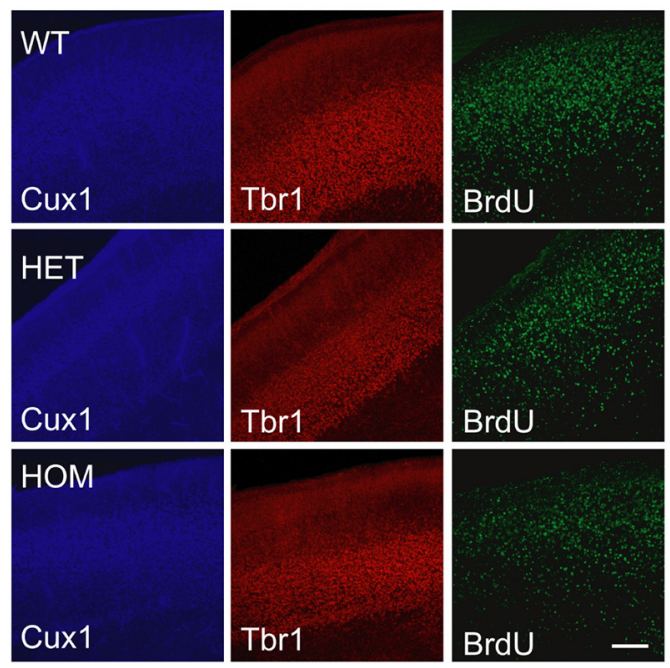

B

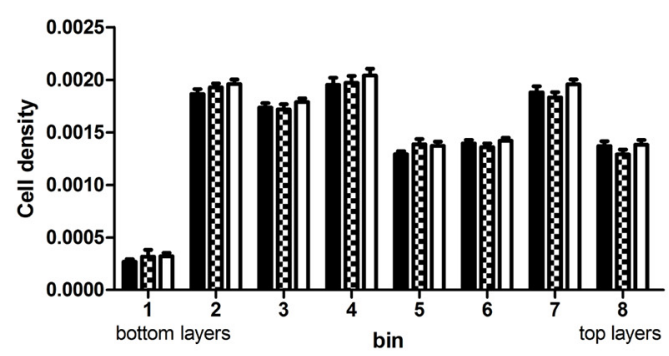

E

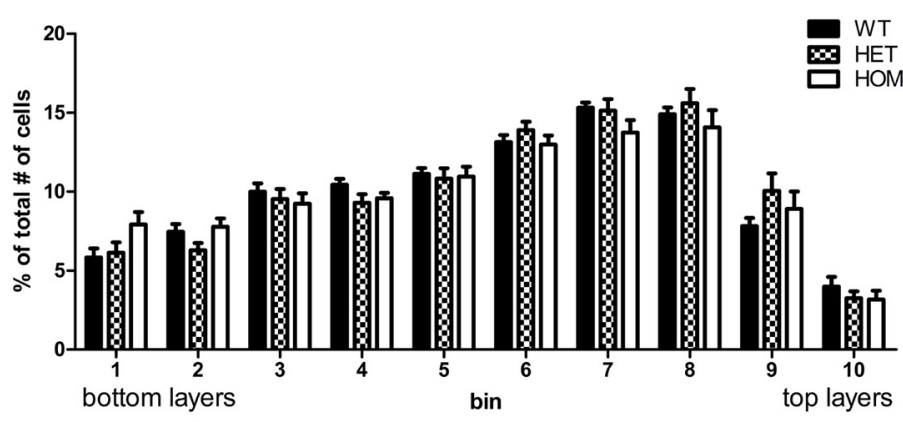

F

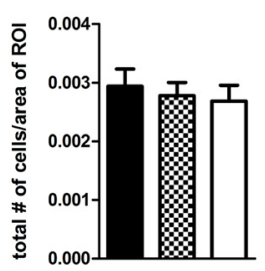

C

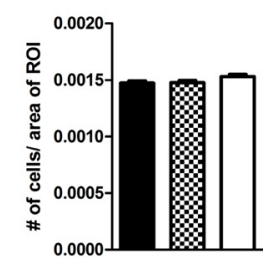

Figure 1. Cortical architecture in Disc1 mutant mice, neuronal progenitor proliferation, neuronal migration, and cortical layer morphology are largely normal in the PFC of Disc1 mutant mice. $\boldsymbol{A}$, Analysis of neuronal density and layer formation in Disc 1 mutant mice. NeuN-positive neurons in adult mice are shown. $\boldsymbol{B}$, NeuN distribution was analyzed across cortical layers encompassed by an ROI divided into 10 equal bins. $C$, The number of NeuN-positive cells in each bin was counted and is shown as a percentage of the number in the entire ROI and as a total number of cells in a ROI. No difference among genotypes was observed ( $n=27,25,24 \mathrm{ROls} ; p=0.93$, two-way RM ANOVA). Scale bar, $100 \mu \mathrm{m}$. D-F, Analysis of BrdU incorporation in cortical neurons in P2 mice. D, Cux1 and Tbr1 were used to label cortical layers. $\boldsymbol{E}$, The distribution of BrdU-labeled neurons was analyzed as for NeuN. No difference was found among the genotypes. The number of BrdU-positive cells in the entire ROI was also not changed ( $\boldsymbol{F} ; n=26,23,22 \mathrm{ROI}, p=1.06$, two-way RM ANOVA). $\mathbf{G}, \boldsymbol{H}$, Quantification of the width of cortical layers II-III labeled by (ux 1 ( $\boldsymbol{G}$ ) and layer VI, labeled by $\operatorname{Tbr} 1(\boldsymbol{H})$. No difference was observed among genotypes ( $n=31,31$, and 28; (ux1, $p=0.50 ;$ Tbr1, $p=0.95$, one-way ANOVA).Values represent the mean \pm SEM. Scale bars, $100 \mu \mathrm{m}$.

onal projections, revealed normal gross distribution of axons within the cortical layers of E18.5 embryos (Fig. 2A). A further quantitative analysis of axon localization did not reveal any change in the spread of axonal fibers (Fig. $2 B, C$; neurofilament, $p=0.27$; $1, p=0.60$ ), suggesting that the development and localization of axonal projections in the cortex is not detectably impacted by Disc1 deficiency.

Previously, layer V pyramidal neurons in the mPFC of Disc1 mutant mice have been shown to display normal complexity and total length of their basal dendritic tree and their apical tuft (Kvajo et al., 2008). To determine the possible effects of the mutation on spine density in this cortical layer, we quantified the numbers of spines on both apical and basal dendrites (Fig. 2D$F)$. No difference was found among the genotypes (apical, $p=0.52$; basal, $p=0.44$ ), suggesting that the cytoarchitecture of layer $\mathrm{V}$ pyramidal neurons in the $\mathrm{mPFC}$ is largely normal in Disc1-deficient mice.

Quantitative proteomic profiling in the prefrontal cortex of Disc1 mutant mice

As a complement to our morphological analysis, $\mathrm{LC}-\mathrm{MS}^{\mathrm{E}}$ profiling was performed with 3- to 5-month-old male littermates to determine the effects of Disc1 deficiency in the prefrontal cortex.
After data filtering, the analysis resulted in the identification of a total of 1044 proteins (in $14 \mathrm{HOM}, 17 \mathrm{HET}$, and $15 \mathrm{WT}$ mice). Following data quality assessment, we found only 17 proteins with nominally significant alterations in the frontal cortex (Table 1). Proteins found altered in this exploratory protein profiling study as well as proteins identified in the literature as interacting with DISC1 were taken forward for targeted SRM analysis. Proteins from the literature included NDEL1 and LIS1, both affected by disrupted DISC1 function (Bradshaw and Porteus, 2012). SRM is an accurate, reproducible, and quantitative technique to measure predetermined sets of proteins (Picotti and Aebersold, 2012). The developed SRM-MS assay validated several protein changes mainly relating to synaptic maintenance, neuronal proliferation, neuronal migration, and apoptosis. Table 2 shows the validation results of the proteins that were taken forward for which at least two peptides were measured using SRMMS. The majority of the proteins were decreased in both HOM and HET mutant mice. Furthermore, both dihydropyrimidinaserelated proteins (DPYLs) were decreased in the heterozygous group and DPYL1 in the homozygous group only, whereas the alterations in MATN4 and HS90A were not reproduced in this follow-up analysis. Also, no differences were found in NDEL1 and LIS1 levels. The decrease of DPYL proteins may indicate 
A
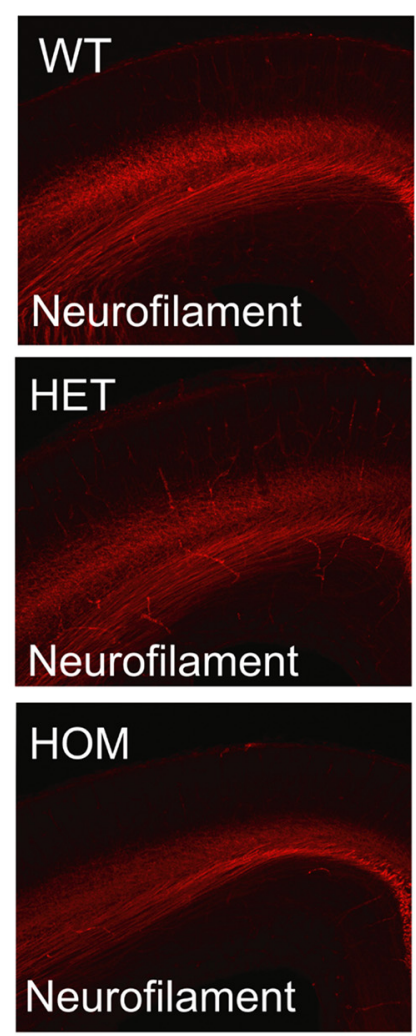
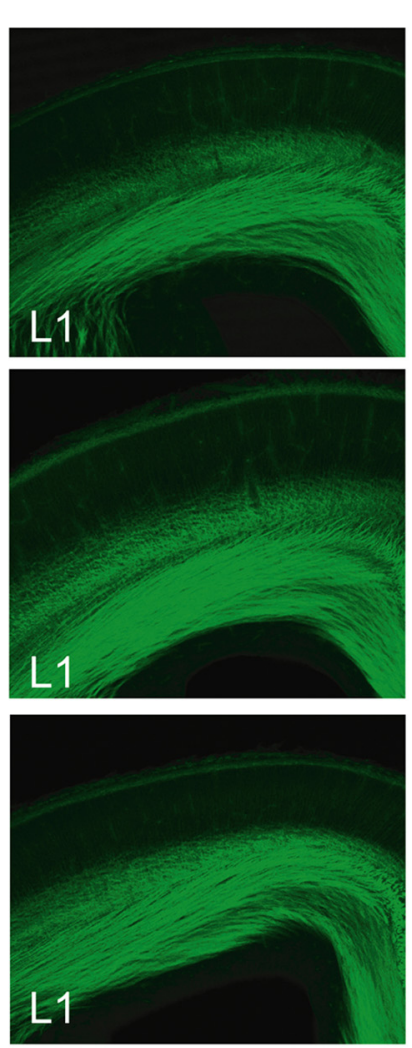
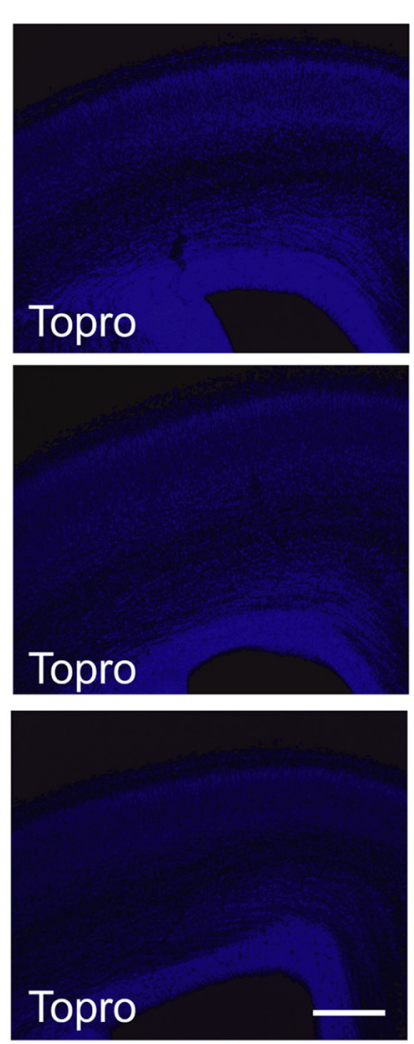

B
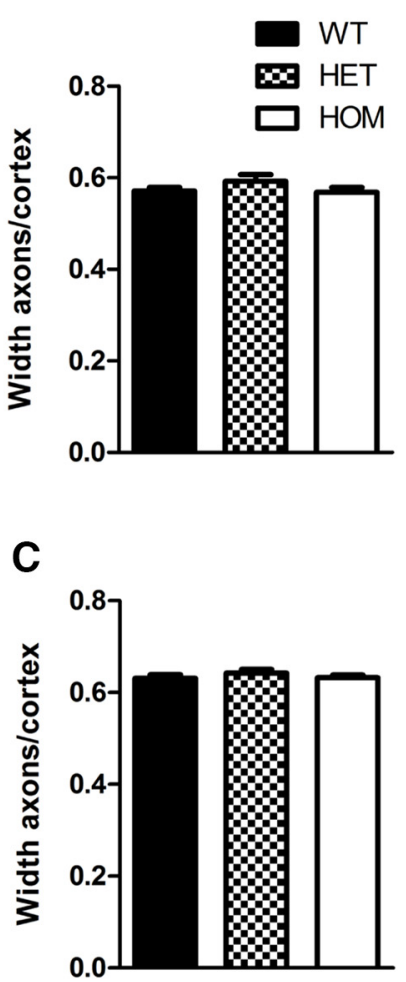

D

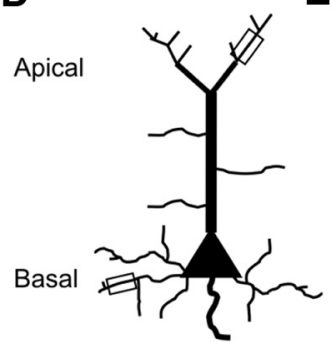

E

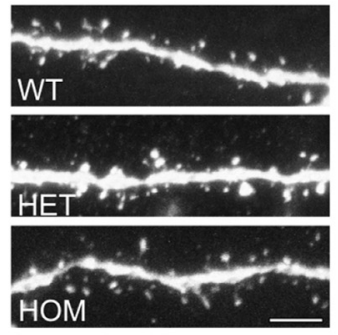

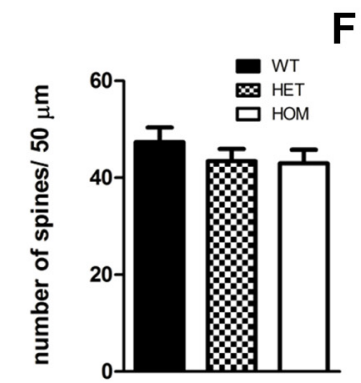

$\mathbf{F}$
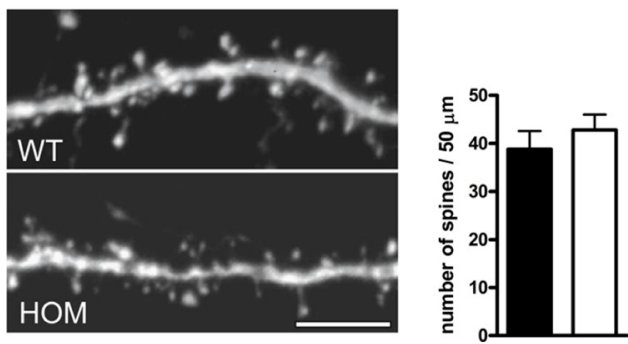

Figure 2. Axonal distribution and cytoarchitecture are largely normal in the PFC of Disc 1 mutant mice. $A$, Analysis of axonal projections in the cortex. E18.5 cortical sections were stained with antibodies against axonal markers neurofilament and L1. The nuclear marker Topro was used to label cells. The localization of axonal tracts was established by measuring their width within the cortical layers. $\boldsymbol{B}, \boldsymbol{C}$, No difference was observed for either neurofilament $(\boldsymbol{B})$ or $\mathrm{L} 1$ ( $\boldsymbol{C}$ labeled axons; $n=33,19,23 \mathrm{ROls:} \mathrm{NF}, p=0.27 ; \mathrm{L} 1, p=0.60$, one-way ANOVA). Values represent the mean \pm SEM. Scale bar, $200 \mu \mathrm{m}$. D. Spine density in PFC layer V pyramidal neurons. Schematic depiction of a pyramidal neuron. Boxed segments represent dendritic regions that were analyzed for spine density. $\boldsymbol{E}, \boldsymbol{F}$, Disc1 mutation does not alter the density of ether apical $(n=16,23,21$ neurons; $p=0.52$, one-way ANOVA; $\boldsymbol{E}$ ) or basal $(n=10$ and 9 neurons; $p=0.44$, unpaired $t$ test; $\boldsymbol{F})$ dendritic spines. Scale bars, $5 \mu \mathrm{m}$. Values represent the mean \pm SEM.

alterations in neuronal migration, axonal outgrowth, and pathfinding (Goshima et al., 1995; Minturn et al., 1995). Changes in DPYLs suggest either that the magnitude of the alteration was not sufficient to lead to a detectable cellular phenotype or that they potentially represent compensatory changes that prevent full expression of the cellular phenotype. Furthermore, a decrease of synaptic vesicle transport, as indicated by changes in ARF4 (Serafini et al., 1991) and a decrease of EEA2, which relates to the reuptake of neurotransmitters (Vandenberg and Ryan, 2013), could partly contribute to the altered synaptic plasticity observed in the frontal cortex of the DISC1 mouse model (see below).

Disc1 mutant mice show enhanced presynaptic axon activation and altered basal synaptic transmission in layer $\mathrm{V}$ of the MPFC

The $\mathrm{mPFC}$ in rodents is thought to play a critical role in cognitive control, including working memory, decision-making, and goal- directed behaviors, analogous to the role of the dorsolateral PFC in primates (Miller and Cohen, 2001). Multiple lines of evidence supports that dysfunction of neural circuits in these regions contributes significantly to the behavioral and cognitive disturbances characteristic of SCZ (Uhlhaas and Singer, 2010). The flow of neuron activity through cortical columns within different laminae is conjectured to provide the neural basis for the coordination of cognitive processes. Pyramidal neurons in layer $\mathrm{V}$ are major projection neurons from the $\mathrm{MPFC}$, and their output activity reflects the results of the integrative information processing performed by local circuits within the mPFC. Afferent fibers arising from superficial cortical layers are an important source of excitatory input to layer $\mathrm{V}$ neurons and thus make an important contribution to cortical computation and information flow (Goldman-Rakic, 1995).

Given our findings indicating largely normal cortical architecture and cytoarchitecture in the PFC, we next sought to deter- 


\begin{tabular}{|c|c|c|c|c|}
\hline \multirow[b]{2}{*}{ Protein } & \multicolumn{2}{|l|}{ WT-HOM mice } & \multicolumn{2}{|l|}{ WT-HET mice } \\
\hline & Ratio Disc1/WT & $P$ & Ratio Disc1/WT & $p$ \\
\hline $1433 B$ & 1.03 & 0.4259 & 1.08 & 0.0258 \\
\hline $1433 G$ & 0.97 & 0.212 & 0.94 & 0.0099 \\
\hline AATM & 0.95 & 0.1705 & 0.93 & 0.0501 \\
\hline AP2B1 & 1 & 0.9585 & 0.93 & 0.0408 \\
\hline ARF4 & 1.14 & 0.3023 & 1.34 & 0.0263 \\
\hline BPHL & 0.94 & 0.4688 & 0.81 & 0.0176 \\
\hline DPYL2 & 0.99 & 0.6338 & 0.96 & 0.0469 \\
\hline EAA2 & 0.95 & 0.2693 & 0.9 & 0.022 \\
\hline EF1A1 & 0.93 & 0.1041 & 0.89 & 0.021 \\
\hline MATN4 & 0.94 & 0.493 & 0.8 & 0.0158 \\
\hline PDZD9 & 0.96 & 0.6226 & 0.83 & 0.0346 \\
\hline PMF1 & 0.91 & 0.3581 & 0.81 & 0.0336 \\
\hline Septin-7 (39326) & 0.98 & 0.5595 & 0.92 & 0.0409 \\
\hline UB2L3 & 0.99 & 0.9374 & 0.78 & 0.0358 \\
\hline CALM & 1.16 & 0.0315 & 1.11 & 0.1139 \\
\hline DPYL1 & 1.07 & 0.0234 & 1.05 & 0.0788 \\
\hline $\mathrm{HS9OA}$ & 1.09 & 0.0309 & 1.08 & 0.0409 \\
\hline
\end{tabular}

The table includes Uniprot ID, ratios (calculated based on average), and $p$ values. Note that the adjusted $p$ value ( $q$ value) for all listed proteins is not significant $(q=0.8620)$. In bold are the proteins with a $p$ value $<0.05$. HS90A, Heat shock protein HSP 90- $\alpha$; CALM, calmodulin; UB2L3, ubiquitin-conjugating enzyme E2 L3; PMF1, polyaminemodulated factor 1; PDZD9, PDZ domain-containing protein 9; MATN4, matrilin-4; EF1A1, elongation factor 1- $\alpha 1$; EAA2, excitatory amino acid transporter 2; BPHL, valacyclovir hydrolase; ARF4, ADP-ribosylation factor 4; AP2B1, AP-2 complex subunit $\beta$; AATM, aspartate aminotransferase; 1433G, 14-3-3 protein $\gamma_{i}$ 1433B, 14-3-3 protein $\beta / \alpha$.

mine whether Disc1 mutant mice displayed alterations in neuronal function within $\mathrm{mPFC}$ that could contribute to neural circuit dysfunction. Field recordings were performed in brain slices on WT and Disc1 mutant mice to examine the synaptic properties in layer $\mathrm{V}$ neurons in response to the stimulation of layer II. Basic synaptic transmission was assessed by examining the input-output relation of synaptic responses. We stimulated presynaptic fibers in layer II with increasing stimulus intensities and recorded the evoked fEPSPs in layer V. The initial, small, nonsynaptic fiber volley was followed by a prominent postsynaptic response (Fig. $3 A$ ). The amplitude of the fiber volley is considered to proportionately reflect the number of presynaptic fibers recruited and serves as an estimate of the magnitude of afferent inputs. The fEPSP was collected from a population of neurons and was quantified by measuring the initial slope of the linear rising phase of the synaptic response (Fig. $3 A$ ). As stimulus intensity increased, the Disc1 mutant mice exhibited significantly greater fEPSP slopes than the wild-type slices (Fig. $3 B ; p=0.039$, two-way RM ANOVA), indicating greater synaptic transmission. To determine whether increased afferent activation contributed to the increase in evoked fEPSP slope in Disc1 mutant mice, the amplitude of fiber volley was measured. We found that, for a given stimulus intensity, Disc1 mutant slices also showed a significantly greater fiber volley amplitude than wild-type slices (Fig. 3C; $p=0.027$, two-way RM ANOVA), indicating a larger presynaptic axon recruitment for a given stimulus consistent with increased excitability of these inputs (Simeone et al., 2013, 2014). Plotting the fEPSP slope against corresponding presynaptic fiber volley amplitude revealed no difference in the distribution of values obtained between genotypes (Fig. $3 D ; p=0.11$, nonlinear regression curve fits). These results suggest that the enhanced basal synaptic transmission observed in layer V mPFC neurons in Disc1 mutant mice appears to result principally from enhanced recruitment of afferent input for a given stimulus intensity rather than from a substantial alteration in baseline synaptic function. Together, these results suggest the possibility that enhanced excitability of afferent inputs to layer $\mathrm{V}$ may be the most prominent alteration in the mPFC of Disc1 mutant mice.

\section{Layer II/III pyramidal neurons in the MPFC of Disc1 mutant mice show enhanced excitability}

Given the apparently normal development and localization of axonal projections of cortical neurons of mutant mice (LepagnolBestel et al., 2013; Fig. 2), we tested whether the increased presynaptic fiber volley detected in layer V field recordings from Disc1 mutant mice could be attributed in part to the increased excitability of neurons in superficial layers synapsing onto layer $\mathrm{V}$ neurons. We used whole-cell recordings to examine intrinsic excitability and membrane properties of layer II-III pyramidal neurons, which give rise to a major source of input to layer $\mathrm{V}$ pyramidal neurons. Action potential firing was assessed in response to incremental depolarizing current injections. Resting membrane potential did not differ between genotypes (WT, $n=$ 8; DISC1-HOM, $n=9$; $-69.1 \pm 1.34$ vs $70.1 \pm 2.11 \mathrm{mV} ; p=$ 0.71 , unpaired $t$ test). Resting membrane potential variation between cells was eliminated by adjusting the resting potential of all neurons to $-70 \mathrm{mV}$ by the injection of a small, standing current. Disc1 mutant neurons fired more action potentials than WT neurons for a given current injection, indicating enhanced excitability (Fig. $4 A, B ; p=0.037$, two-way RM ANOVA). The rheobase current was reduced in Discl mutant neurons but did not reach significance (Fig. $4 C ; p=0.30$ ). The afterhyperpolarization (AHP) of the action potential did not differ between genotypes and thus could not account for excitability differences (Fig. 4C; $p=0.89)$. Furthermore, input resistances did not differ between WT and Disc1 mutant neurons (Fig. $4 C$; WT, $n=8$; DISC1$\mathrm{HOM}, n=9 ; 154 \pm 15.3$ vs $148 \pm 14.0 \mathrm{M} \Omega ; p=0.46$, unpaired $t$ test), suggesting that the observed excitability difference was likely due to differences in voltage-dependent conductances rather than differences in passive membrane properties.

\section{Disc1 mutant mice demonstrate multiple alterations in short-term synaptic plasticity suggestive of enhanced neurotransmitter release}

Although our findings suggested predominant alterations in presynaptic neuronal excitability without major alterations in basal synaptic function (Fig. 3), we further explored whether synaptic plasticity was altered in Disc1 mutant mice. While both shortterm and long-term synaptic plasticity alterations have been implicated in the pathogenesis of multiple neuropsychiatric diseases, recent convergent findings suggest a potentially critical role for dysfunction of short-term plasticity in underlying the prominent short-term information processing deficits found in SCZ (Arguello and Gogos, 2012; Crabtree and Gogos, 2014). To determine whether short-term synaptic plasticity was altered in Disc1 mutant mice, we assessed the synaptic event PPR in layer V of the mPFC. While both genotypes exhibited synaptic facilitation at short interstimulus intervals (PPR $>1$ at 50 and $100 \mathrm{~ms}$ intervals), Disc1 mutant mice showed reduced PPR compared with WT mice throughout the entire range of interstimulus intervals strongly suggesting that Disc1 mutant synapses had elevated the initial $\mathrm{P}_{\mathrm{r}}$ compared with $\mathrm{WT}$ synapses (Zucker and Regehr, 2002; Fig. 5A, $B ; p=0.032$, two-way RM ANOVA). These data suggest that Disc1 mutant mice have alterations in presynaptic function that lead to enhanced neurotransmitter release.

To further assess short-term synaptic plasticity, we next examined STD in response to trains of stimuli. STD is elicited upon 
Table 2. Validation of candidate proteins identified in frontal cortex tissue of HOM and HET Disc1-mutant mice alongside WT mice using SRM-MS

\begin{tabular}{|c|c|c|c|c|c|c|}
\hline \multirow[b]{2}{*}{ Protein } & \multicolumn{3}{|l|}{ WT-HOM mice } & \multicolumn{3}{|l|}{ WT-HET mice } \\
\hline & Ratio Disc1/WT & $p$ & $q$ & Ratio Disc1NT & $p$ & $q$ \\
\hline ARF4 (P61750) & 0.83 & 0.0275 & 0.0554 & 0.72 & 0.0004 & 0.0013 \\
\hline EAA2 (P43006) & 0.84 & 0.0277 & 0.0554 & 0.79 & 0.0019 & 0.0046 \\
\hline 1433B (Q9CQV8) & 0.57 & $2.50 \times 10^{-11}$ & $3.05 \times 10^{-10}$ & 0.75 & $1.44 \times 10^{-5}$ & $8.65 \times 10^{-5}$ \\
\hline 1433G (P61982) & 0.61 & $1.50 \times 10^{-9}$ & $9.29 \times 10^{-9}$ & 0.86 & 0.0082 & 0.0163 \\
\hline DPYL1 (P97427) & 0.96 & 0.5187 & 0.7780 & 0.86 & 0.0276 & 0.0457 \\
\hline DPYL2 (008553) & 0.69 & $4.00 \times 10^{-5}$ & 0.0002 & 0.82 & 0.0304 & 0.0457 \\
\hline MATN4 (089029) & 0.99 & 0.9119 & 0.9687 & 0.84 & 0.1335 & 0.1602 \\
\hline HS90A (P07901) & 1.00 & 0.9687 & 0.9687 & 0.89 & 0.19 & 0.2072 \\
\hline
\end{tabular}

Selected proteins were either identified in the discovery study (Table 1) or previously linked to Disc 1 function. The table includes Uniprot ID, ratios (calculated based on average), $p$ values ( $p$ ), and adjusted $p$ values ( $q$ values). In bold are the proteins with a $p$ value $<0.05$. HS90A, P07901, Heat shock protein HSP 90- $\alpha$; MATN4 (089029), matrilin-4; 1433G (P61982), 14-3-3 protein $\gamma$; 1433B (Q9CQV8), 14-3-3 protein $\beta / \alpha$; EAA2 (P43006), excitatory amino acid transporter 2; ARF4 (P61750), ADP-ribosylation factor 4.

repetitive presynaptic activity and plays a critical role in neural circuit computation (Abbott and Regehr, 2004). We thus analyzed STD at a range of physiologically relevant frequencies (Miller et al., 1996) with 40 stimuli delivered at 5-50 $\mathrm{Hz}$. In response to these stimulus trains, rapid depression of synaptic events was observed in both genotypes, most likely attributable to the depletion of a readily releasable pool (RRP) of neurotransmitter vesicles (Zucker and Regehr, 2002). Disc1 mutant mice, however, showed significantly greater synaptic depression at lower stimulus frequencies $(5-20 \mathrm{~Hz})$, but not at higher stimulus frequencies $(40-50 \mathrm{~Hz})$, compared with WT mice (Fig. $5 C, D ; p=$ 0.0089 at $5 \mathrm{~Hz} ; p=0.0046$ at $10 \mathrm{~Hz}$; $p=0.0084$ at $20 \mathrm{~Hz} ; p=0.095$ at $40 \mathrm{~Hz}$; $p=0.22$ at $50 \mathrm{~Hz}$; two-way RM ANOVA). This enhanced short-term depression observed in Discl mutant mice again suggests an increased presynaptic probability of neurotransmitter release at Disc1 mutant synapses, here leading to more rapid depletion of the RRP and resulting in enhanced STD (Zucker and Regehr, 2002).

We next used an LTP induction protocol that allowed us to assess both LTP as well as STP in Disc1 mutant mice (Volianskis and Jensen, 2003). To determine the impact of Discl deficiency on the potentiation of synaptic efficacy in layer V of mPFC, STP and LTP were induced as previously described (Fénelon et al., 2011, 2013). While STP was observed in both Disc1 mutant and WT mice, we observed that STP was modestly but not significantly enhanced in Disc1 mutant mice (Fig. $5 E, F ; p=0.078$, two-way RM ANOVA). Similarly, assessing LTP 40 min after repeated tetani revealed no significant difference between genotypes (Fig. $5 F ; p=0.067$, two-way RM ANOVA). Together, the results indicate pervasive alterations in short-term synaptic plasticity in the absence of long-term plasticity alterations. Furthermore, the short-term plasticity alterations observed in Disc1 mutant mice together suggest altered presynaptic function characterized by enhanced neurotransmitter release (Zucker and Regehr, 2002).
B

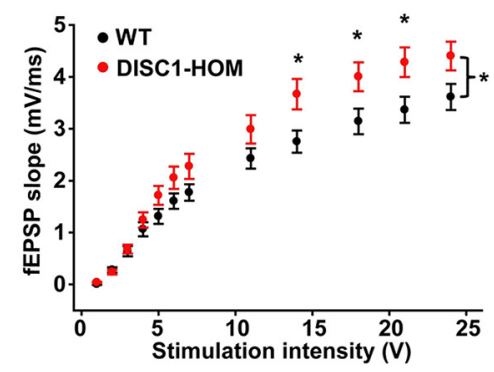

D

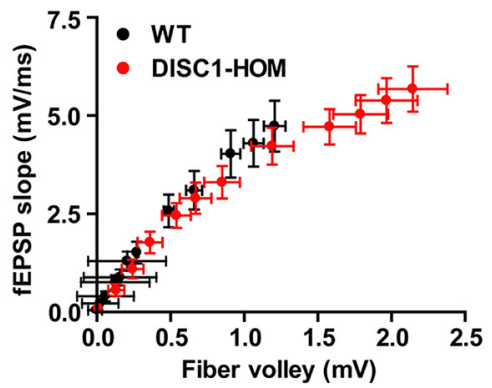

Figure 3. Enhanced recruitment of inputs to mPFC layer V in Disc1 mutant mice. A, Sample traces of field EPSP (WT, black traces; DISC1-HOM, red traces) obtained in response to incrementally increased stimulus intensities and showing the measurement of the amplitude of the fiber volley (blue arrow) and the slope of the fEPSP (blue line). Scale bars, $0.5 \mathrm{mV}$ and $10 \mathrm{~ms}$. $\boldsymbol{B}$, The fEPSP input - output relationship is significantly enhanced in DISC1-HOM mice across a wide range of stimulus intensities (WT mice: black dots, $N=16, n=41$; DISC1-HOM mice: red dots, $N=19, n=42$; two-way RM ANOVA, $p=0.039$; post hoc testing; ${ }^{*} p<0.05$ ). (black dots, $N=13, n=22$ ) across a wide range of stimulus intensities (two-way RM ANOVA, $p=0.027$; post hoc testing, ${ }^{* *} p<$ $0.01,{ }^{* * *} p<0.001$ ). D, Plot of fEPSP slope against corresponding presynaptic fiber volley amplitude for WT (black dots; $N=13$, $n=22$ ) and DISC1-HOM mice (red dots; $N=15, n=22$ ) shows no difference in the distribution of values obtained between genotypes (comparison of fits, $p=0.11$ ), indicating no difference in basal synaptic strength.

Layer II/III pyramidal neurons in the mPFC of Disc1 mutant mice show reduced voltage-gated potassium currents near action potential threshold

To investigate the potential underlying mechanisms of the enhanced excitability we observed in layer II/II pyramidal neurons in Disc1 mutant mice, we assessed currents in these neurons known to be involved with determining action potential generation. As there were no differences in input resistance or capacitance between WT and Discl mutant neurons that could explain observed excitability differences, we investigated whether there were differences in voltage-gated sodium and potassium currents between genotypes that might be able to explain the increased excitability in Disc1 mutant neurons. Whole-cell voltage-clamp recordings using incremental depolarizing voltage steps from 
A

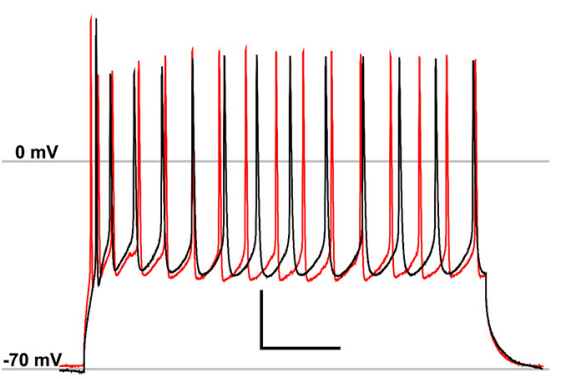

B

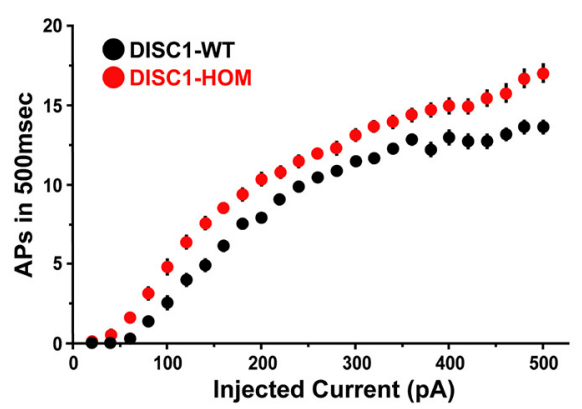

C

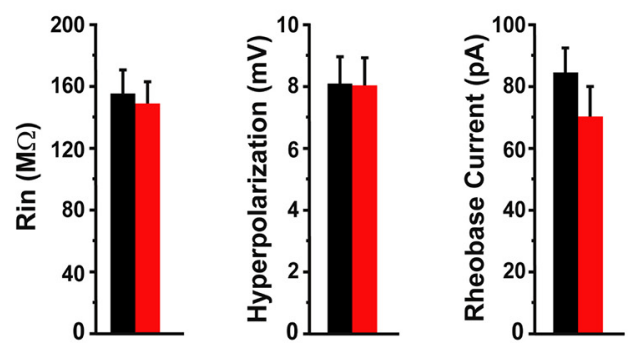

Figure 4. Enhanced excitability of mPFC layer II//II pyramidal neurons in Disc 1 mutant mice. A, Disc1 mutant neurons display enhanced excitability (red trace) compared with WT neurons (black trace). Representative traces from current-clamp recordings from layer II/III pyramidal neurons showing near-maximal AP responses to a $400 \mathrm{pA}$ current step. Calibration: $20 \mathrm{mV}, 100$ ms. Reference levels, $V_{\text {rest }}=-70$ and $0 \mathrm{mV}$. $\boldsymbol{B}$, Summary data (mean \pm SEM) of the number of APs evoked in response to $500 \mathrm{~ms}$ currents steps. WT recordings, black; DISC1-HOM recordings, red (WT, DISC1-HOM: $n=8, n=9$; two-way RM ANOVA, $p=0.037$ ). Values represent the mean \pm SEM. C, Summary data (mean \pm SEM) of input resistance $\left(R_{\mathrm{in}^{\prime}}\right.$ left), AHP (middle), and rheobase current ( $I_{\text {rheo, }}$ right). WT recordings, black; DISC1-HOM recordings, red (WT, $n=8 ;$ DISC1-HOM, $n=9 ; \mathrm{R}_{\mathrm{in},} p=0.58 ; \mathrm{AHP}, p=0.80 ; \mathrm{I}_{\text {rheo, }}, p=0.30$ ).

$-70 \mathrm{mV}$ were used to activate voltage-gated channels. Series resistance $\left(\mathrm{R}_{\mathrm{ser}}\right)$ errors were partially corrected $(70 \%$ prediction, $85 \%$ series resistance compensation) and did not differ systematically between recordings from WT and Disc1 mutant neurons (WT, $n=10, \mathrm{R}_{\text {ser }}=18.4 \pm 1.9 \mathrm{M} \Omega$; DISC1-HOM, $n=8, \mathrm{R}_{\text {ser }}=$ $16.7 \pm 3.6 \mathrm{M} \Omega ; p=0.33$, unpaired $t$ test). While there are inherent technical limitations with the voltage-clamp technique that preclude precise quantification of fast, voltage-gated sodium currents in our recordings from neurons with complex, nonideal morphology, the absence of significant alterations in neuronal morphology and dendritic complexity in PFC pyramidal neurons in Discl mutant mice suggest that comparisons of the relative magnitudes of these fast, transient inward currents between genotypes might remain potentially informative (Kvajo et al., 2008). The peak magnitude of the transient inward currents elicited by voltage steps to either $-40 \mathrm{mV}$ [approximating $\mathrm{AP}$ threshold voltage $\left.\left(\mathrm{V}_{\text {thresh }}\right)\right]$ or $0 \mathrm{mV}$ did not differ between WT and DISC1-HOM neurons (Fig. $6 A, B ;-40 \mathrm{mV}, p=0.22 ; 0 \mathrm{mV}$, $p=0.30$; unpaired $t$ test). In contrast, however, the magnitude of the potassium currents elicited by voltage steps to either -40 or 0 $\mathrm{mV}$ were markedly reduced in Disc1 mutant neurons compared with WT neurons, suggesting that a reduction of these potassium currents near AP threshold voltages likely accounted for the observed increased excitability in Disc1 mutant neurons (Li et al., 2011; Fig. 6A, $C$; $-40 \mathrm{mV}, p=0.0047 ; 0 \mathrm{mV}, p=0.0072$ ).

\section{Selective reduction in $\mathrm{K}_{\mathrm{v}} 1.1$ expression and function} underlies enhanced excitability in Disc1 mutant neurons

To determine whether the changes observed in voltage-gated currents were in part due to changes in the expression of sodium and potassium channels, we performed qRT-PCR analysis in the PFC of Disc1 mutant mice and wild-type littermates. Based upon kinetic properties and prominent expression in cortical pyramidal neurons, we hypothesized that $\mathrm{Na}_{\mathrm{v}} 1.6$ and $\mathrm{K}_{\mathrm{v}} 1.1$ were the most likely candidates responsible for contributing to the currents assessed in electrophysiology assays (Fig. 6A-C). Paralleling electrophysiology results, the analysis of PFC expression levels with qRT-PCR revealed a small reduction in $\mathrm{Na}_{\mathrm{v}} 1.6$ and a marked reduction in $\mathrm{K}_{\mathrm{v}} 1.1$ expression in Discl mutant mice compared with WT mice (Fig. $6 D$; $\mathrm{Na}_{\mathrm{v}} 1.6$ vs DISC1-HET, $p<0.05 ; \mathrm{Na}_{\mathrm{v}} 1.6$ vs DISC1-HOM, $p<0.01 ; \mathrm{K}_{\mathrm{v}} 1.1$ vs DISC1-HET, $p<0.05 ; \mathrm{K}_{\mathrm{v}} 1.1$ vs DISC1-HOM, $p<0.001$; one-way ANOVA). To determine whether reduced $\mathrm{K}_{\mathrm{v}} 1.1$ expression was uniquely responsible for the reduced voltage-dependent potassium currents observed in Discl mutant mice, we examined the expression of additional $\mathrm{K}_{\mathrm{v}}$ family candidates with similar near-threshold activation properties as $\mathrm{K}_{\mathrm{v}} 1.1$ and with known expression in neocortical pyramidal neurons. Analysis of PFC expression levels of $\mathrm{K}_{\mathrm{v}} 1.2, \mathrm{~K}_{\mathrm{v}} 1.3, \mathrm{~K}_{\mathrm{v}} 1.6$, and $\mathrm{K}_{\mathrm{v}} 2.1$ revealed no differences in Disc1 mutant mice compared with WT mice (Fig. $6 E ; \mathrm{K}_{\mathrm{v}} 1.2, p=0.44 ; \mathrm{K}_{\mathrm{v}} 1.3, p=0.083$; $\mathrm{K}_{\mathrm{v}} 1.6, p=0.26 ; \mathrm{K}_{\mathrm{v}} 2.1, p=0.60$; unpaired $t$ test). Together, electrophysiology and expression results specifically implicated reduced functional expression of $\mathrm{K}_{\mathrm{v}} 1$ 1.1-containing channels as a substantial underlying cause of the hyperexcitability observed in Disc1 mutant neurons.

\section{Acute pharmacological blockade of $\mathrm{K}_{\mathrm{v}} 1.1$ in WT neurons recapitulates the enhanced excitability observed in Disc1 mutant neurons}

To further explore whether reduced functional expression of $\mathrm{K}_{\mathrm{v}} 1.1$ was indeed a significant cause of hyperexcitability of Disc 1 mutant neurons, we examined the effects of acute pharmacological blockade of $\mathrm{K}_{\mathrm{v}} 1.1$ upon the excitability of layer II/III pyramidal neurons. We assessed excitability with whole-cell recordings in which current steps were used to evoke APs, both before and after the application of DTX-K (100 nM), a specific blocker of $\mathrm{K}_{\mathrm{v}} 1$.1-containing channels. In agreement with our initial excitability finding (Fig. 4A,B), before the application of DTX-K, layer II/II pyramidal neurons in Disc1 mutant brain slices showed enhanced AP generation compared with WT neurons (Fig. 7B; $p=0.019$, two-way RM ANOVA). Furthermore, in WT layer II/III pyramidal neurons, DTX-K significantly enhanced the excitability compared with pretreatment levels as DTX-K application increased AP generation responses to a given current step-which is comparable to the excitability levels observed in untreated Disc1 mutant neurons-indicating that $\mathrm{K}_{\mathrm{v}} 1.1$ containing channels normally exert a suppressive influence on excitability in these neurons (Fig. $7 A, B ; p=0.032$, two-way RM ANOVA). In contrast, this same experimental paradigm revealed 
A

B
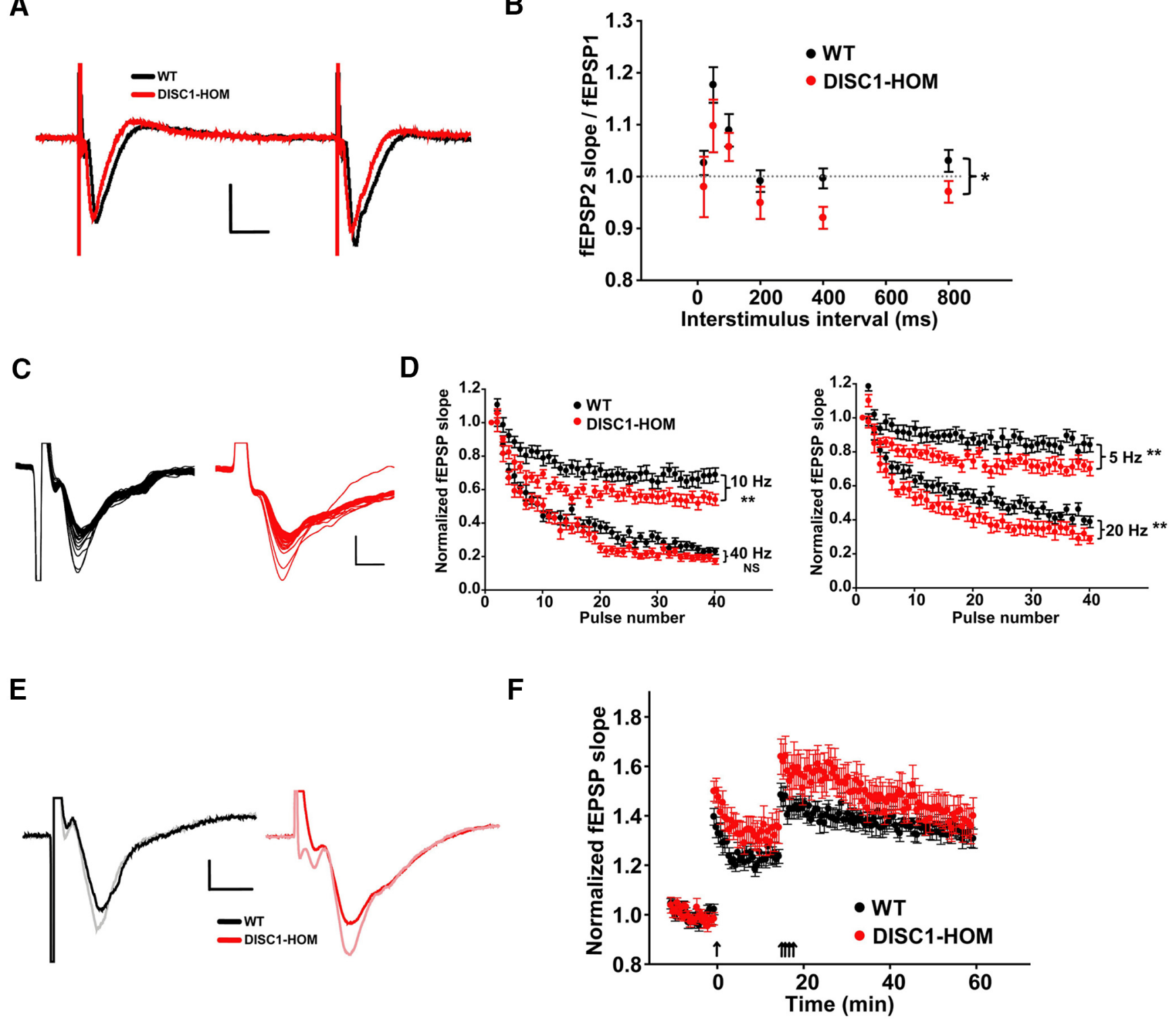

Figure 5. Disc 7 mutant mice display multiple alterations in short-term synaptic plasticity, suggesting enhanced presynaptic neurotransmitter release. $A$, Paired-pulse ratio fEPSP representative traces (WT, black trace and DISC1-HOM, red trace) obtained at an interstimulus interval (ISI) of $50 \mathrm{~ms}$. Calibration: $1 \mathrm{mV}$ and $10 \mathrm{~ms}$. B, PPR is significantly decreased in DISC1-HOM mice (red dots, N = $6, n=17$ ) compared with WT controls (black dots, $N=6, n=21$ ) over the range ISIs of $20-800 \mathrm{~ms}(p=0.032$, two-way RM ANOVA). $C$, Representative traces of superimposed fEPSP responses from WT (black traces) and DISC1-HOM mice (red traces) evoked by 40 stimuli applied at $10 \mathrm{~Hz}$. Calibration: $0.5 \mathrm{mV}$ and $5 \mathrm{~ms}$. D, STD shows a frequency-dependent difference between genotypes. STD is significantly greater in DISC1-HOM mice (red dots, $N=6, n=18$ ) than WT mice (black dots, $N=6, n=22$ ) during 5,10 , and $20 \mathrm{~Hz}$ trains (stimulation frequency $\times$ genotype interaction; $5 \mathrm{~Hz}, p=0.0089 ; 10 \mathrm{~Hz}, p=0.0046 ; 20 \mathrm{~Hz}, p=0.0084$, two-way RM ANOVA) but is comparable between genotypes during $40 \mathrm{~Hz}$ trains $(p=0.095$, two-way RM ANOVA). $\boldsymbol{E}$, STP sample traces of fEPSP before (WT, black trace; DISC1-HOM, red trace) and immediately after the first tetanization (WT, gray trace; DISC1-HOM, pink traces). $F$, STP and LTP in WT (black dots, $N=11, n=15$ ) and DISC1-HOM mice (red dots, $N=12, n=16)$. There is a nonsignificant enhancement of STP immediately after the first $50 \mathrm{~Hz}$ train (first arrow) in DISC1-HOM mice $(p=0.0784$, two-way RM ANOVA). After four consecutive $50 \mathrm{~Hz}$ trains (four arrows), long-term potentiation assayed $40 \mathrm{~min}$ post-tetanization is comparable between genotypes ( $p=0.067$, two-way RM ANOVA). Values represent the mean \pm SEM.

that DTX-K failed to enhance excitability in Disc1 mutant II/III pyramidal neurons, consistent with the markedly decreased $\mathrm{K}_{\mathrm{v}} 1.1$ expression in Disc1 mutants (Fig. 6D), leading to a markedly reduced contribution of $\mathrm{K}_{\mathrm{v}} 1.1$-containing channels in suppressing excitability in Disc 1 mutant neurons (Fig. $7 B ; p=0.41$, two-way RM ANOVA).

The fact that we observed almost no effect upon excitability after DTX-K blockade of $\mathrm{K}_{\mathrm{v}} 1.1$ in Disc1 mutant neurons despite residual $\mathrm{K}_{\mathrm{v}} 1.1$ expression suggests the possibility of a nonlinear impact of $\mathrm{K}_{\mathrm{v}} 1.1$ expression levels upon excitability that could potentially arise from mechanisms ranging from channel assembly dynamics up to the level of the complex functional interplay among the channels responsible for regulating excitability. Although $\mathrm{K}_{\mathrm{v}} 1$ family channels have been implicated in contributing to the afterhyperpolarization (Glazebrook et al., 2002), $\mathrm{K}_{\mathrm{v}} 1.1$ blockade with DTX-K had no significant effect on afterhyperpolarization (Fig. 7C; WT vs DISC1-HOM, $p=0.83$; WT vs WTDTX, $p=0.43$; DISC1-HOM vs DISC1-HOM-DTX, $p=0.39$ ), which is consistent with our finding that the AHP was unaltered in Disc1 mutant neurons. $\mathrm{K}_{\mathrm{v}} 1.1$ blockade did not reduce the rheobase current in Disc1 mutant neurons, whereas it caused a modest, although nonsignificant, reduction in the rheobase current in WT neurons [Fig. 7C; WT vs DISC1-HOM, $p=0.50$; WT vs WT-DTX, $p=0.98$; DISC1-HOM vs DISC1-HOM-DTX, $p=$ 
A

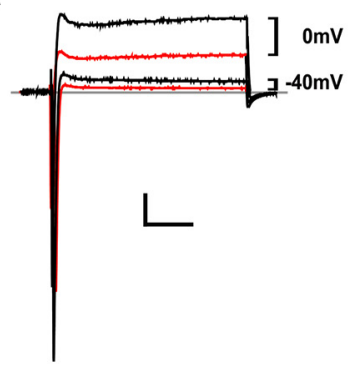

D

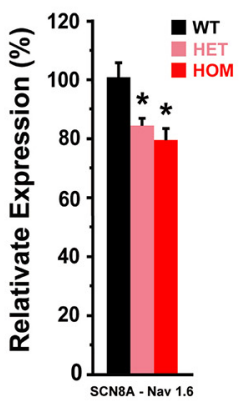

B

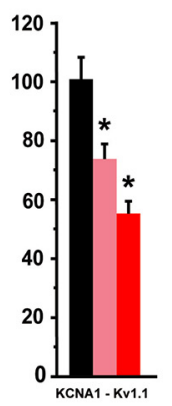

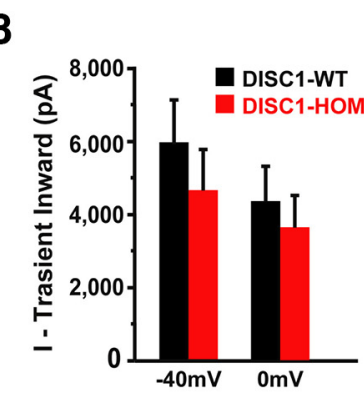

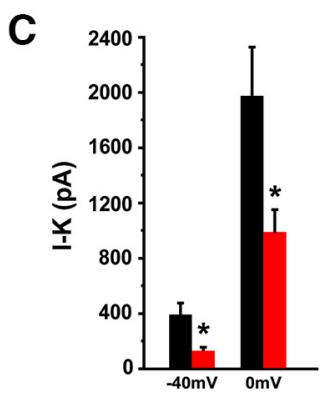

E

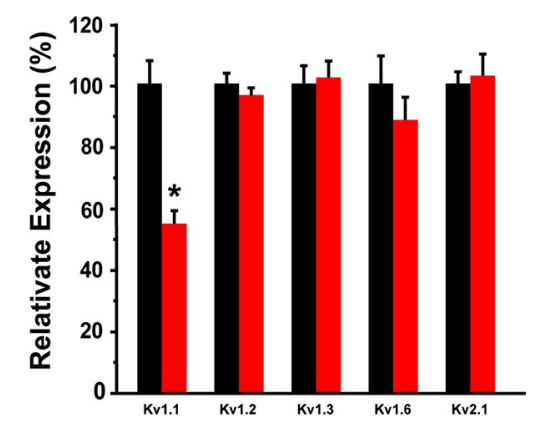

Figure 6. Selective reductions in $\mathrm{K}_{\mathrm{v}} 1.1$ in Disc1 mutant mice may underlie hyperexcitability in Disc1 mutant mice. A, Disc1 mutant neurons display reduced voltage-dependent potassium currents (red traces) compared with WT neurons (black traces). Representative traces from voltage-clamp recordings from layer II/III pyramidal neurons showing activation of fast, transient inward currents and noninactivating potassium currents in response to voltage steps from -70 to $-40 \mathrm{mV}$ (near $\mathrm{V}_{\mathrm{AP} \text {-thresh }}$ ) and $0 \mathrm{mV}$. Calibration: 500 pA, $25 \mathrm{~ms}$. Reference level: holding current at $\mathrm{V}_{\text {rest }}=-70 \mathrm{mV}$. $\boldsymbol{B}$, Transient inward currents -including major contributions from voltage activated sodium currents - show modest yet nonsignificant reductions in $\mathrm{mPFC}$ layer II/III pyramidal neurons in Disc1 mutant mice. Summary data (mean \pm SEM) of peak fast, transient currents evoked by voltage steps from $-70 \mathrm{mV}$ to indicated voltages. WT, black bars; DISC1-HOM, red bars. (WT, DISC1-HOM: $n=10, n=8$; unpaired $t$ test: step to $-40 \mathrm{mV}, p=0.22 ; 0 \mathrm{mV}, p=0.30$ ). C, Summary data (mean $\pm \mathrm{SEM}$ ) of steady-state potassium currents evoked by voltage steps from $-70 \mathrm{mV}$ to the indicated voltage. WT, blackbars; DISC1-HOM, red bars (WT, $n=10$; DISC1-HOM, $n=8$; unpaired $t$ test: step to $-40 \mathrm{mV}, p=0.0047 ; 0 \mathrm{mV}, p=0.0072)$. D, PFC mRNA expression of $\mathrm{K}_{\mathrm{v}} 1.1$ and $\mathrm{Na}_{\mathrm{v}} 1.6$ are reduced in Disc 1 mutant mice. Summary qRT-PCR data (mean \pm SEM) of $\mathrm{K}_{\mathrm{v}} 1.1$ and Na 1.6 expression in PFC (normalized to $100 \%$ for WT levels). WT, black bars; DISC1-HET, pink bars, DISC1-HOM, red bars (WT, $n=7$; DISC1-HET, $n=6$; DISC1-HOM, $n=6$; one-way ANOVA: Na 1.6 :

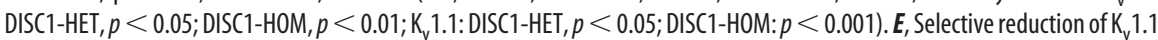
in Disc 1 mutant mouse PFC. qRT-PCR data (mean $\pm S E M$ ) of $K_{v} 1.1, K_{v} 1.2, K_{v} 1.3, K_{v} 1.6$, and $K_{v} 2.1$ expression in PFC (normalized to $100 \%$ for WT levels). WT, black bars; DISC1-HOM, red bars (WT, $n=7 ; \mathrm{DISC1}-\mathrm{HOM}, n=6$; unpaired $t$ test: $\mathrm{K}_{\mathrm{v}} 1.1, p=0.0003 ; \mathrm{K}_{v} 1.2$, $p=0.44 ; K_{v} 1.3, p=0.083 ; K_{v} 1.6, p=0.26 ;$ and $\left.K_{v} 2.1, p=0.60\right)$.

0.11 (NS)]. Together, these results using highly specific pharmacological blockade of $\mathrm{K}_{\mathrm{v}} 1.1$-containing channels (Robertson et al., 1996; Bagchi et al., 2014), coupled with results showing isolated and marked reductions in expression of $\mathrm{K}_{\mathrm{v}} 1.1$ in the PFC of Disc1 mutant mice (Fig. 6D,E), strongly suggest that the enhanced neuronal excitability observed in Discl mutant mice is likely largely the result of reduced functional expression of $\mathrm{K}_{\mathrm{v}} 1.1$ containing channels.

Reduced functional expression of $\mathrm{K}_{\mathrm{v}} 1.1$ in Disc1 mutant mice contributes to enhanced presynaptic neurotransmitter release and altered short-term plasticity

We next investigated whether the reduced functional expression of $\mathrm{K}_{\mathrm{v}} 1$.1-containing channels in Disc1 mutant mice was further responsible for the alterations observed in short-term synaptic plasticity, which had suggested enhanced presynaptic neurotransmitter release (Fig. 5). Alterations in voltage-dependent potassium channels have been shown to impact synaptic function and plasticity. Specifically, in addition to effects upon excitability, reduced expression, inactivation, or blockade of $\mathrm{K}_{\mathrm{v}}$ family channels, including $\mathrm{K}_{\mathrm{v}} 1.1$, can lead to action potential widening, which can dramatically facilitate neurotransmitter release through the enhanced AP-evoked $\mathrm{Ca}^{2+}$ influx that results from prolonged activation of voltage- dependent calcium channels present at presynaptic terminals (Borst and Sakmann, 1999; Geiger and Jonas, 2000; Brew et al., 2003; Guan et al., 2007; Kole et al., 2007). To assess whether the reductions in $\mathrm{K}_{\mathrm{v}} 1.1$ expression and function we observed in Disc1 mutant mice were associated with AP widening that could enhance neurotransmitter release, we compared single, isolated action potentials in layer II/III pyramidal neurons in Disc1 mutant and WT mice. Consistent with reduced functional expression of $\mathrm{K}_{\mathrm{v}} 1.1$, action potentials in Disc1 mutant mice, although showing unchanged rise rates, displayed significant widening and significantly slower decay rates compared with action potentials in WT neurons (Fig. $8 A, B$; AP width, $p=0.020$; rise rate, $p=$ 0.23 ; decay rate, $p=0.030)$. While the AP rise rate was reduced in Disc1 mutant neurons, this reduction was not statistically significant, possibly due to the only modest reductions observed in $\mathrm{Na}_{\mathrm{v}} 1.6$ expression (Fig. 6D), which may not be sufficient to affect the overwhelming functional dominance of the voltage-gated sodium channel conductance during the rising phase of the action potential. These results support that reductions of $\mathrm{K}_{\mathrm{v}} 1.1$ functional expression in Disc1 mutant mice lead to significant AP widening that would likely prolong APmediated depolarization of presynaptic terminals and thus lead to enhanced initial $\mathrm{P}_{\mathrm{r}}$ at Disc1 mutant synapses.

As action potential widening in Discl mutant neurons predicted the possibility of enhanced neurotransmitter release from the presynaptic terminals of these neurons, we next investigated whether reductions in $\mathrm{K}_{\mathrm{v}} 1.1$ function were responsible for the alterations in short-term synaptic plasticity observed in Disc1 mutant mice that likewise suggested enhanced neurotransmitter release (Fig. 5). To determine whether the reduced $\mathrm{K}_{\mathrm{v}} 1.1$ expression in Disc1 mutant mice caused the synaptic differences we observed in $\mathrm{mPFC}$, DTX-K was applied to selectively block $\mathrm{K}_{\mathrm{v}}$ 1.1-containing channels (Gittelman and Tempel, 2006). Synaptic responses were quantified by measuring the input-output curves before and during DTX-K (100 nM) application (Fig. $8 C, D)$. To overcome the variation of basal synaptic responses among individual slices and to highlight the differential effects of DTX-K between genotypes, synaptic responses were normalized within genotypes to the maximal synaptic response before DTX application (Fig. 8E,F). We found that DTX-K significantly enhanced the input-output relation in WT mice but was without significant effect upon Disc1 mutant mice (Fig. 8E, WT, $p=$ 0.0044; Fig. $8 F$, DISC1-HOM, $p=0.36$; two-way RM ANOVA; Fig. $8 C, D)$. Analysis of fiber volley amplitude before and after DTX-K, while not reaching statistical significance, is consistent with the possibility of a similar genotype-specific effect of DTX-K whereby fiber volley amplitude in WT mice appeared enhanced but was largely unaffected in Disc1 mutant mice (Fig. 8G, WT, $p=0.26$; Fig. $8 H, p=0.65$, two-way RM ANOVA). 
A

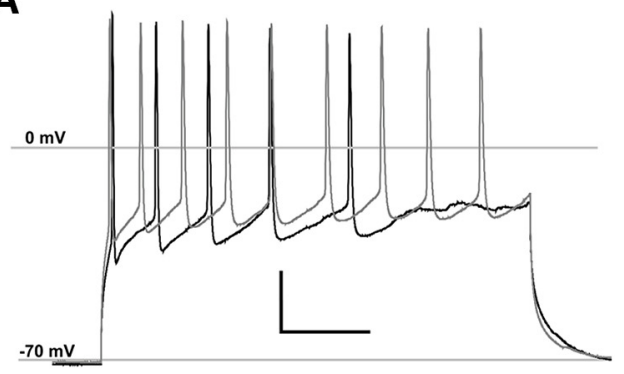

B

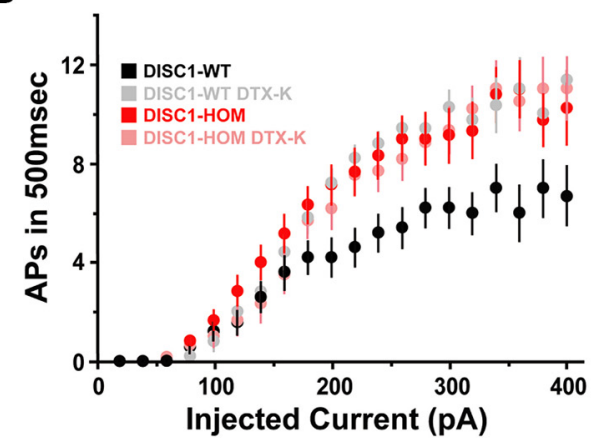

C
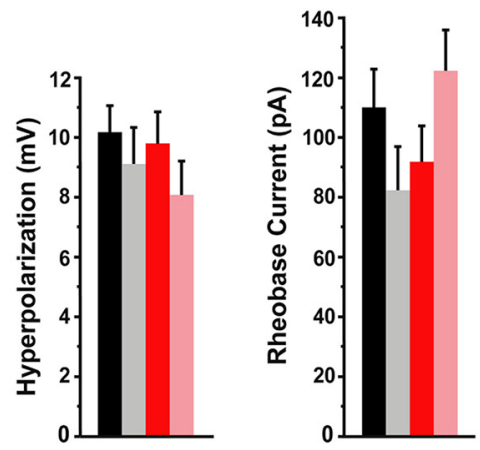

Figure 7. Selective pharmacological blockade of $\mathrm{K}_{\mathrm{v}} 1.1$ causes enhanced excitability of mPFC layer II/III pyramidal neurons. $A$, WT neurons in the presence of the selective $\mathrm{K}_{\mathrm{v}} 1.1$ blocker DTX-K (100 nm) display enhanced excitability (gray trace) compared with pretreatment excitability levels (black trace). Representative traces from current-clamp recordings from layer II/III pyramidal neurons showing AP responses to a 250 pA current step. Calibration: 20 mV, 100 ms. Reference levels: $V_{\text {rest }}=-70$ and $0 \mathrm{mV}$. $\boldsymbol{B}$, Summary data (mean $\pm \mathrm{SEM}$ ) of number APs evoked in response to 500 ms currents steps. WT, black; WT-DTX, gray; DISC1-HOM, red; DISC1HOM-DTX, pink [WT \pm DTX, $n=8$; DISC1-HOM \pm DTX, $n=7$; two-way RM ANOVA: WT vs DISC1-HOM, $p=0.019$; WT vs WT-DTX, $p=0.032 ;$ DISC1-HOM vs DISC1-HOM-DTX, $p=0.41$ (NS)]. Values represent the mean \pm SEM. C, Summary data (mean \pm SEM) of AHP (left) and rheobase current $\left(\mathrm{I}_{\text {rheo, }}\right.$, right) before and during $\mathrm{K}_{\mathrm{v}} 1.1$ blockade with $100 \mathrm{~nm}$ DTX-K. WT recordings, black; in DTX-K, gray; DISC1-HOM recordings, red; in DTX-K, pink [WT \pm DTX, $n=8$; DISC1-HOM \pm DTX, $n=7$; AHP: WT vs DISC1-HOM, $p=0.83$; WT vs WT-DTX, $p=0.43$; DISC1-HOM vs DISC1-HOM-DTX, $p=0.39 ;$ I $_{\text {reo, }}$ WT vs DISC1-HOM, $p=0.50$; WT vs WT-DTX, $p=0.18$; DISC1-HOM vs DISC1-HOM-DTX, $p=0.11$ (NS)].

These data suggest that $\mathrm{K}_{\mathrm{v}} 1.1$ normally exerts a suppressive action upon synaptic transmission in WT mice and that the enhanced synaptic transmission observed in Discl mutant mice (Fig. 3A,B) - and the lack of effect of $\mathrm{K}_{\mathrm{v}} 1.1$ blockade in these mice-results in part from an absence of this suppressive action due to the profound reduction in the functional expression of $\mathrm{K}_{\mathrm{v}} 1$ 1-1-containing channels in Disc1 mutant mice (Fig. 6C,D). As this experiment, however, could not resolve whether reduced $\mathrm{K}_{\mathrm{v}} 1.1$ function enhanced synaptic transmission through en- hanced presynaptic excitability (Fig. 3B-D) or through enhanced neurotransmitter release, we further explored the potential impact of $\mathrm{K}_{\mathrm{v}} 1.1$ on synaptic function by assessing short-term synaptic plasticity.

To directly test whether the alterations in short-term plasticity observed in Disc1 mutant mice that are consistent with enhanced neurotransmitter release (Fig. $5 A-D$ ) resulted from the reduced functional expression of $\mathrm{K}_{\mathrm{v}} 1.1$, we next examined the effects of $\mathrm{K}_{\mathrm{v}} 1.1$ blockade on short-term plasticity. The paired-pulse ratio of synaptic responses was tested before and during DTX application in Disc1 mutant and WT mice. Before DTX-K application, Disc1 mutant mice showed significantly reduced PPR compared with WT mice, confirming our previous results that were consistent with enhanced neurotransmitter release in Disc1 mutant mice (Fig. $8 I, p=0.037$, two-way RM ANOVA; Fig. $5 A, B$ ). In the presence of DTX-K, the paired-pulse ratio in WT mice was reduced to a level indistinguishable from that of untreated Disc1 mutant mice, while DTX-K was without effect upon the PPR of Disc1 mutant mice (Fig. $8 I, p=0.72$, two-way RM ANOVA). As such, $\mathrm{K}_{\mathrm{v}} 1.1$ blockade abolished the difference in PPR between genotypes. Furthermore, because $\mathrm{K}_{\mathrm{v}} 1.1$ blockade led to enhanced neurotransmitter release in WT mice but was without effect in Disc1 mutant mice, there is a strong suggestion that the enhanced neurotransmitter release observed in mutant mice was largely due to the reduced functional expression of $\mathrm{K}_{\mathrm{v}} 1.1$.

We further tested whether the enhanced STD observed during stimulus trains in Disc1 mutant mice was in part due to reduced $\mathrm{K}_{\mathrm{v}} 1.1$ function. Similar to paired-pulse studies, we found that the application of DTX-K abolished the differences in STD between genotypes (Figs. $5 D, 8 J ; p=0.38$ at $5 \mathrm{~Hz}, p=0.33$ at $10 \mathrm{~Hz}$, and $p=0.11$ at $20 \mathrm{~Hz}$, two-way RM ANOVA).

Together, these results showing that $\mathrm{K}_{\mathrm{v}} 1.1$ blockade (1) mimics in WT mice the synaptic alterations found in Discl mutant mice, (2) has no detectable effect upon synaptic function in mutant mice, and (3) eliminates detectable differences in synaptic function between genotypes strongly argue that the proximate deficit underlying the synaptic alterations in Disc1 mutant mice, arises primarily due to reduced the functional expression of $\mathrm{K}_{\mathrm{v}} 1.1$ channels in afferent excitatory inputs within mPFC layer V. We performed a series of additional experiments to refine and solidify this basic tenet of our model.

Many cellular mechanisms are known to regulate both synaptic transmission and short-term synaptic plasticity. Alterations in voltage-gated calcium channels (VGCCs) or intracellular calcium stores, for example, could directly impact neurotransmitter release probability and thus short-term synaptic plasticity (Rose and Konnerth, 2001; Catterall and Few, 2008). Recent studies suggested the possibility that intracellular $\mathrm{Ca}^{2+}$ store function (Park et al., 2015; Tsuboi et al., 2015) and VGCC function (Tang et al., 2016) may be altered by Disc1 deficiency. Although our ensemble results implicating $\mathrm{K}_{\mathrm{v}} 1.1$ hypofunction as primarily responsible for excitability and synaptic plasticity alterations in our Disc1 mutant mice would be difficult to reconcile with primary alterations in VGCCs or intracellular $\mathrm{Ca}^{2+}$ store function, we also explored whether these two important mechanisms that modulate short-term synaptic plasticity were altered in Disc1 mutant mice. To assess these possibilities, we used fura- $2 \mathrm{Ca}^{2+}$-imaging studies of neuronal cell bodies in cultured cortical neurons. These studies indicated a small but significant elevation in resting cytosolic $\mathrm{Ca}^{2+}$ in Disc1 mutant neurons ( $p=0.030$; Fig. 9A). Responses to high potassium challenges $(50 \mathrm{~mm}, 15 \mathrm{~s})$, however, showed no detectable alterations in $\mathrm{Ca}^{2+}$ fluxes in Disc1 mutant neurons ( $p=0.28$; Fig. $9 A$ ), indicating that voltage-gated cal- 
A

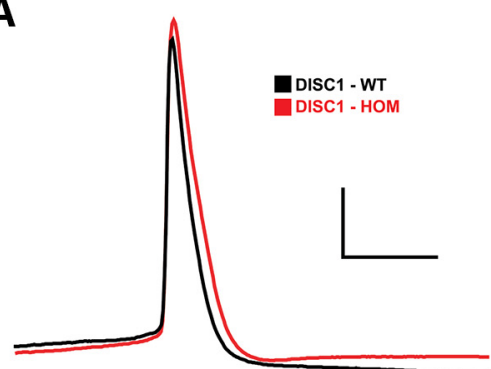

C

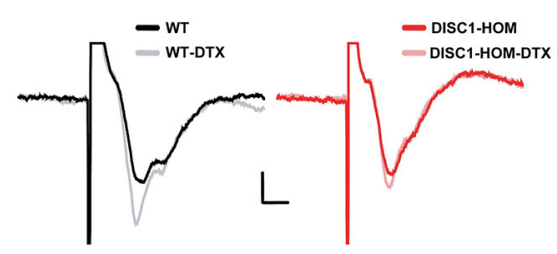

E

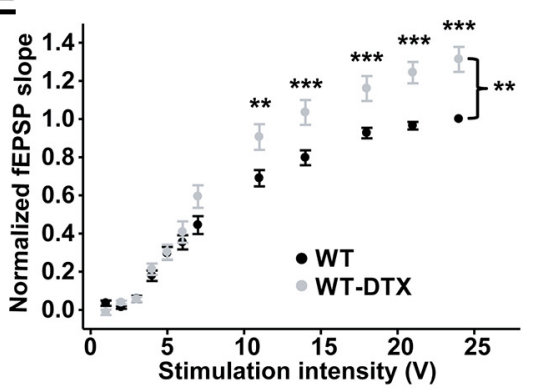

G

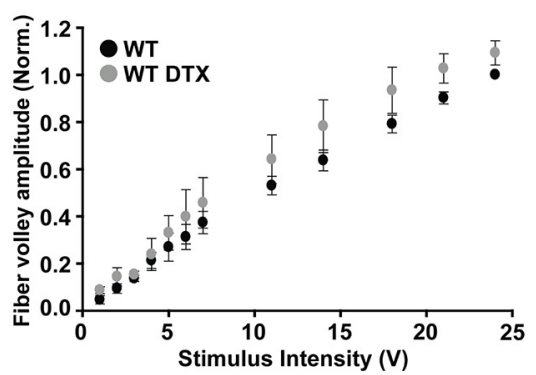

I

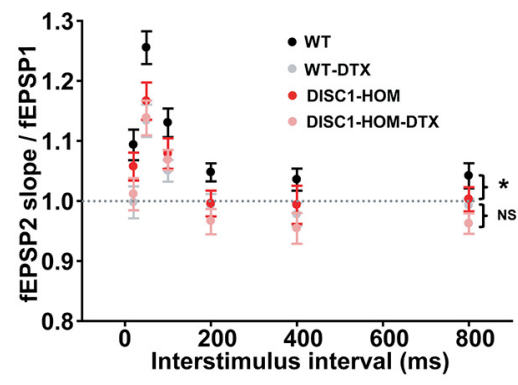

B

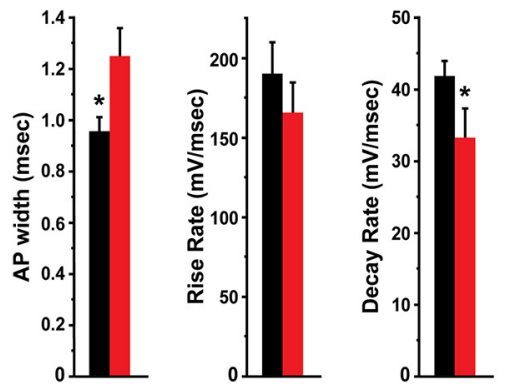

D

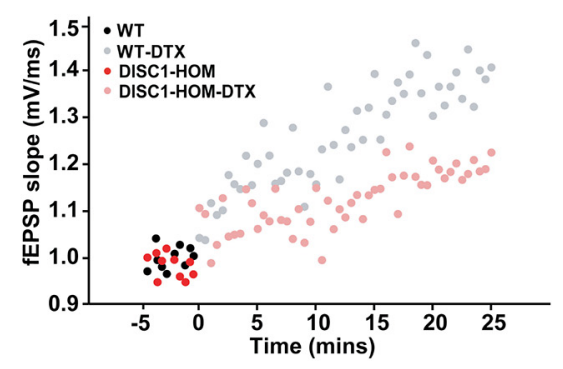

$\mathbf{F}$

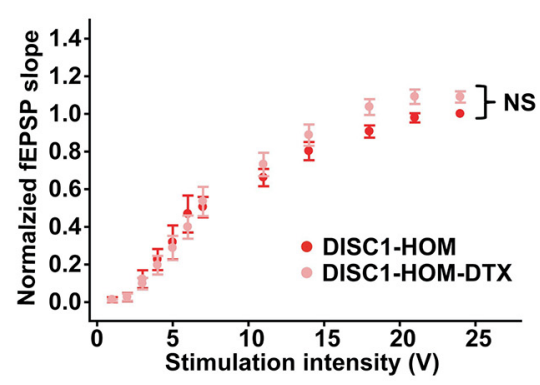

H

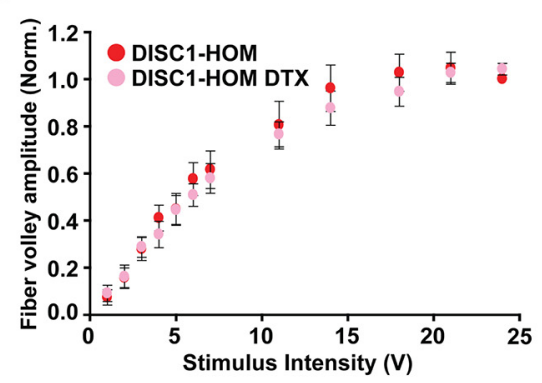

J

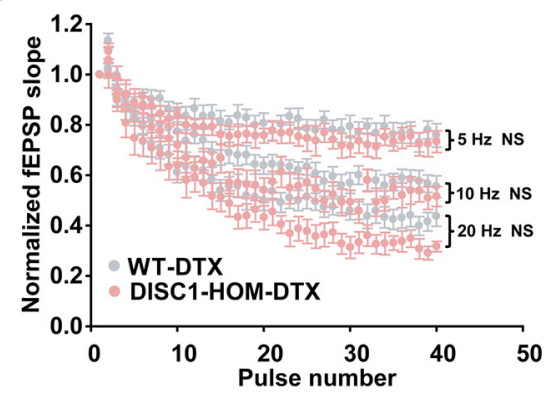

Figure 8. Reductions in $K_{v} 1.1$ function in Disc1 mutant mice cause altered short-term synaptic plasticity consistent with enhanced neurotransmitter release. A, Disc1 mutant neurons display AP widening (red trace) compared with WT neurons (black trace). Representative traces from current-clamp recordings from layer II/III pyramidal neurons showing AP responses to a minimal, threshold current step. Calibration: $20 \mathrm{mV}, 5 \mathrm{~ms}$. B, Summary data (mean \pm SEM) of AP width (left), rise rate (center), and decay rate (right). WT recordings, black bars; DISC1-HOM recordings, red bars (WT, $n=8 ;$ DISC1-HOM, $n=10$; paired $t$ test: width,

cium channel function was not likely substantially different between genotypes. Similarly, assays of intracellular $\mathrm{Ca}^{2+}$ store function revealed that neither the percentage of responding neurons nor the amplitude of $\mathrm{Ca}^{2+}$ responses was altered in Disc1 mutant mice. Calcium responses to caffeine challenges $(10 \mathrm{~mm}, 30 \mathrm{~s})$ to assess ryanodine-sensitive $\mathrm{Ca}^{2+}$ stores revealed no detectable alterations in Disc1 mutant neurons (percentage responders, $p=0.22 ; \mathrm{Ca}^{2+}$ response amplitude, $p=$ 0.18; Fig. $9 B$ ). Likewise, calcium responses to ATP challenges $(100 \mu \mathrm{M}, 1 \mathrm{~min})$ to assess $\mathrm{IP}_{3}$-receptor-sensitive $\mathrm{Ca}^{2+}$ stores revealed no detectable alterations in Disc1 mutant neurons (percentage of responders, $p=0.68$; $\mathrm{Ca}^{2+}$ response amplitude, $p=0.77$; Fig. $9 C$ ). Together, these results

$\leftarrow$

$p=0.020$; rise rate, $p=0.23$; decay rate, $p=0.030$ ). C, Sample traces offEPSP before (WT, black traces;DISC1-HOM, red traces) and 25 min after DTX-K application (WT, gray traces; DISC1-HOM pink traces). D, Time course of onset of DTX-K action highlights enhanced impact upon synaptic transmission in WT compared with Disc1-mutant mice. Representative example of change in fEPSP slope from before (WT, black dots; Disc1 mutant, red dots) and during100 nм DTX-K application over 25 min (WT, gray dots; Disc1 mutant, pink dots). DTX-K begins to result in increased fEPSP slope after $\sim 5 \mathrm{~min}$ and reaches a plateau after $\sim 20 \mathrm{~min}$ DTX-K perfusion. $\boldsymbol{E}$, The normalized input- output relation of WT mice before (black dots) and after 100 nм DTX-K application (gray dots). DTX-K significantly increases the synaptic responses of WT mice $(N=7$, $n=14, p=0.044$, two-way RM ANOVA). Post hoc analysis, ${ }^{* *} p<0.01,{ }^{* * *} p<0.001$. Data are normalized to maximum fEPSP slope value before DTX-K application. $\boldsymbol{F}$, The normalized input- output relation of Disc 7 mutant mice before (red dots) and after DTX-K application (pink dots), showing that DTX-K does not affect synaptic responses in Disc 1 mutant mice significantly $(N=7, n=14 ; p=0.364$, two-way RM ANOVA). Data are normalized to maximum fEPSP slope value before DTX-K application. G, Afferent fiber volley amplitudes in WT mice before (black) and during (gray) DTX-Kapplication. Data are normalized to untreated response at maximal stimulation $(N=5$, $n=7$; two-way RM ANOVA, $p=0.26$; post hoc testing revealed no significant differences). $\boldsymbol{H}$, Afferent fiber volley amplitudes in Disc1 mutant mice before (red) and during (pink) DTX-K application. Data are normalized to untreated response at maximal stimulation ( $N=5, n=7$; two-way RM ANOVA, $p=0.26$; post hoc testing revealed no significant differences). I, PPR of WT and Disc 1 mutant mice before and after DTX-K application. Before applying DTX-K, Disc1 mutant mice (red dots, $N=7, n=14$ ) exhibit a significantly decreased PPR across the range of ISIs compared with WT mice (black dots, $N=7, n=14 ; p=0.0375$, two-way RM ANOVA). This difference in PPR is abolished by $100 \mathrm{~nm}$ DTX-K application (WT and Disc 1 mutant, gray and pink dots, respectively, $p=0.718$, two-way RM ANOVA). J, Short-term depression of WT (gray dots; $N=7, n=14$ ) and DISC1-HOM (pink dots; $N=7, n=$ 14) mice after $100 \mathrm{~nm}$ DTX-Kapplication, elicited by 5,10 , and $20 \mathrm{~Hz}$ stimulus trains. In DTX-K, there is no difference in STD between genotypes $(5 \mathrm{~Hz}, p=0.38 ; 10 \mathrm{~Hz}, p=0.33 ; 20 \mathrm{~Hz}$, $p=0.11$; two-way RM ANOVA). Values represent mean \pm SEM. 
A

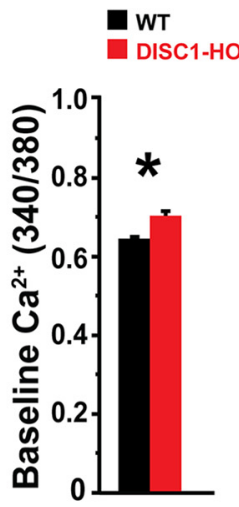

B

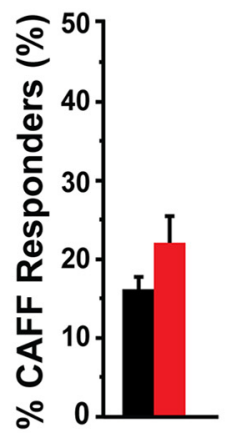

C

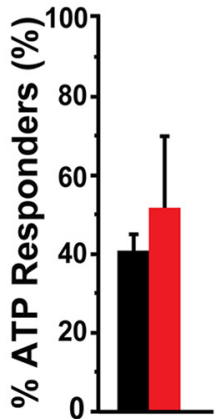

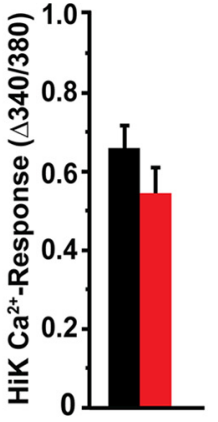
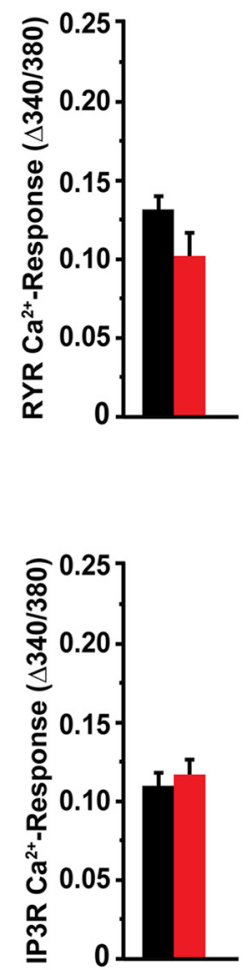

Figure 9. The function of voltage-gated calcium channels and intracellular $\mathrm{Ca}^{2+}$ stores are largely unaltered in Disc 1 mutant mice. $A$, Summary data (mean \pm SEM) of resting intracellular $\mathrm{Ca}^{2+}$ (resting fura-2,340/380 nm; left) and peak $\mathrm{Ca}^{2+}$ responses to high potassium challenges (HiK; $50 \mathrm{~mm} \mathrm{KCl}$, peak 340/380 response; right) in cultured cortical neurons (neurons/preparations: WT, $n=1001 / 3$; DISC1-HOM, $n=1110 / 3$; baseline 340/380 ratio, $p=0.0297$; peak HiK $340 / 380$ response, $p=0.283$, paired $t$ tests). $\boldsymbol{B}$, Summary data (mean \pm SEM) of caffeineevoked $\mathrm{Ca}^{2+}$ responses (caffeine 10mm, CAFF; percentage of responding neurons, left; peak $340 / 380$ response, right) in cultured cortical neurons (neurons/preparations: WT, $n=1001 / 3$; DISC1-HOM, $n=1110 / 3$; percentage of neurons responding, $p=0.222$; peak caffeine-evoked $340 / 380$ response, $p=0.178$; decay rate, paired $t$ tests). C, Summary data (mean \pm SEM) of ATP-evoked $\mathrm{Ca}^{2+}$ responses (ATP, $100 \mu \mathrm{m}$; percentage responding neurons, left; peak 340/380 responses, right) in cultured cortical neurons (neurons/preparations: WT, $n=629 / 3$; DISC1HOM, $n=832 / 3$; percentage of neurons responding, $p=0.683$; peak caffeine-evoked 340/ 380 response, $p=0.772$; decay rate, paired $t$ tests).

suggest that the function of both voltage-gated $\mathrm{Ca}^{2+}$ channels and intracellular $\mathrm{Ca}^{2+}$ stores are unaltered in cortical neurons of Disc1 mutant mice. It should be noted, however, that these results obtained from neuronal somata may not necessarily quantitatively reflect the function of these processes within presynaptic terminals where neurotransmitter release is directly regulated. Despite this limitation, our results suggest that alterations in ei- ther of these processes are unlikely to be the primary underlying cause of the synaptic alterations we observed.

Our results suggest that the synaptic plasticity alterations we observed in Discl mutant mice arose most likely due to $\mathrm{K}_{\mathrm{v}} 1.1$ hypofunction in excitatory neurons synapsing onto layer $\mathrm{V}$ neurons. It is possible, however, that $\mathrm{K}_{\mathrm{v}} 1.1$ hypofunction in inhibitory GABAergic neurons may be contributing through an indirect mechanism. $\mathrm{A} \mathrm{K}_{\mathrm{v}} 1.1$ hypofunction in inhibitory neurons could lead to enhanced GABA release- due to AP wideningfrom these neurons (Brew et al., 2003; Begum et al., 2016). The resultant enhanced GABA release could in turn act to suppress glutamate release through a heterosynaptic mechanism involving enhanced GABA-mediated activation of presynaptic $\mathrm{GABA}_{\mathrm{B}}$ receptors on glutamatergic terminals (Davies et al., 1990; Dutar and Nicoll, 1988; but see also Brenowitz et al., 1998; Yamada et al., 1999). Such indirect GABAergic effects could in theory contribute to the alterations in synaptic plasticity we observed in Disc1 mutant mice (Fig. 5C,D). To address this possibility, we reassessed short-term synaptic depression in Disc1 mutant mice during $\mathrm{GABA}_{\mathrm{B}}$ receptor blockade (CGP54626, $10 \mu \mathrm{M}$ ) to eliminate a possible modulatory contribution of $\mathrm{GABA}_{\mathrm{B}}$ receptor activation to the excitatory short-term depression.

We found that $\mathrm{GABA}_{\mathrm{B}}$ receptor blockade had no detectable effect upon the dynamics of excitatory short-term synaptic depression during stimulus trains in either WT or mutant mice (Fig. 10; effect of $\mathrm{GABA}_{\mathrm{B}}$ blockade at 5, 10, and $20 \mathrm{~Hz}$ : WT, $p=$ $0.76, p=0.99$, and $p=0.13$; DISC1-HOM, $p=0.46, p=0.91$, $p=0.24$; two-way RM ANOVAs). These results indicate that any potential influence of $\mathrm{GABA}_{\mathrm{B}}$ receptor activation at these synapses under our stimulation conditions is at most very minor and therefore it would be unlikely that any potential alteration in $\mathrm{GABA}_{\mathrm{B}}$ receptor activation at these synapses would be able to account for the altered short-term depression we observed in Discl mutant mice (Figs. 5C,D, 10). These results thus further support the notion that the short-term depression alterations we observed in Disc1 mutant mice arise due to $\mathrm{K}_{\mathrm{v}} 1.1$ hypofunction directly in the afferent excitatory inputs synapsing onto layer $\mathrm{V}$ neurons rather than through an indirect mechanism involving GABAergic neurons.

One potential additional implication of $\mathrm{K}_{\mathrm{v}} 1.1$ hypofunction in these excitatory neurons synapsing in layer $\mathrm{V}$ might be that these neurons could have enhanced rates of spontaneous APs at rest and that this could result in enhanced sEPSCs detected in layer $\mathrm{V}$ neurons. It is unclear, however, whether the reduced expression of $\mathrm{K}_{\mathrm{v}} 1.1$ would lead to enhanced rates of spontaneous APs under resting conditions in excitatory neurons in general or, more specifically, in the excitatory neurons under study here that synapse in layer $\mathrm{V}$ of the $\mathrm{mPFC}$. In fact, there are a number of reasons to suspect that $\mathrm{K}_{\mathrm{v}} 1.1$ hypofunction may not lead to a substantial enhancement of the spontaneous AP rate in excitatory neurons.

First, $\mathrm{K}_{\mathrm{v}} 1.1$ channels only begin to show significant activation near the AP threshold voltage (Grissmer et al., 1994; Bekkers and Delaney, 2001; Brew et al., 2003; Guan et al., 2007), suggesting that at resting membrane potentials alterations in $\mathrm{K}_{\mathrm{v}} 1.1$ levels would have little direct influence upon either the resting membrane potential (Brew et al., 2003; Guan et al., 2007) or the generation of spontaneous APs in otherwise quiescent neurons. Second, although $\mathrm{K}_{\mathrm{v}}$ 1.1-null mice show spontaneous seizures (Smart et al., 1998) and complete deletion or blockade of $\mathrm{K}_{\mathrm{v}} 1.1$ leads to enhanced rates of spontaneous, AP-driven synaptic events arising from GABAergic neurons (Southan and Robertson, 1998a,b; Tan and Llano, 1999; Zhang et al., 1999; Herson et 
A

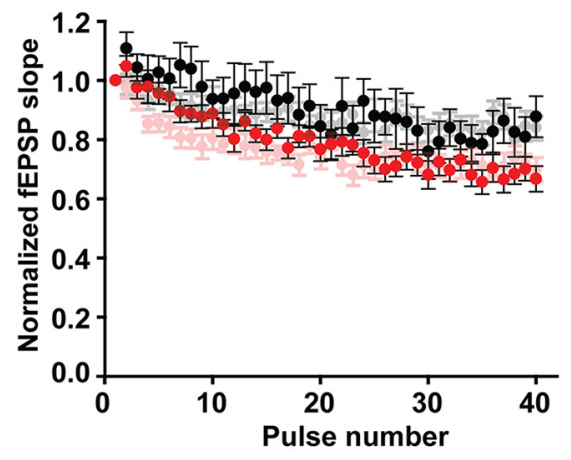

B

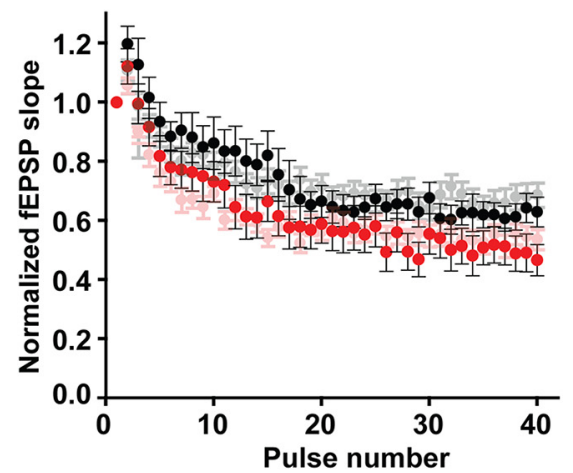

C

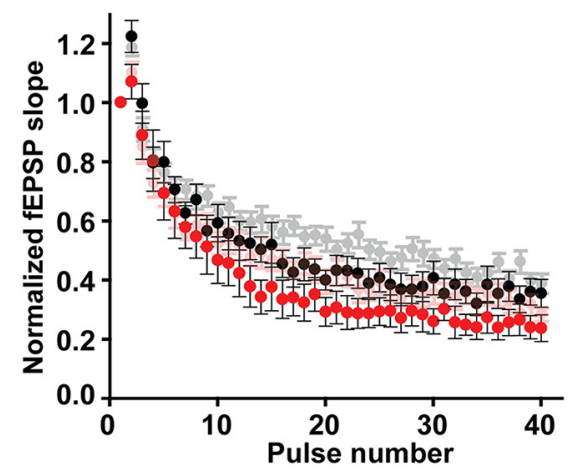

Figure 10. Altered short-term synaptic plasticity in Disc1 mutant mice is unlikely due to alterations in $G_{A B A_{B}}$ modulation. STD of excitatory synaptic transmission in mPFC layer $V$ during stimulus trains is not significantly affected by endogenously recruited $G_{A B A_{B}}$ receptormediated modulation. Summary data of STD in WT (black dots, $N=3, n=10$ ) and DISC1-HOM (red dots, $N=4, n=13$ ) during $\mathrm{GABA}_{\mathrm{B}}$ receptor blockade (GP-54626, $10 \mu \mathrm{M}$ ). Data overlaid onto data from untreated WT (gray) and DISC1-HOM (pink) STD experiments (data from Fig. 4D). $\boldsymbol{A}-\boldsymbol{C}, \mathrm{STD}$ during $5 \mathrm{~Hz}(\boldsymbol{A}), 10 \mathrm{~Hz}(\boldsymbol{B})$, and $20 \mathrm{~Hz}(\boldsymbol{C})$ stimulus trains (stimulation frequency $\times$ drug treatment interaction: WT vs $(\mathrm{GP}-54626$-treated WT: $5 \mathrm{~Hz}, p=0.76 ; 10 \mathrm{~Hz}, p=0.99 ; 20$ $\mathrm{Hz}, p=0.13$; DISC1-HOM vs CGP-54626-treated DISC1-HOM: $5 \mathrm{~Hz}, p=0.46 ; 10 \mathrm{~Hz}, p=0.91$; $20 \mathrm{~Hz}, p=0.24$; two-way RM ANOVAs). Values represent the mean \pm SEM.

al., 2003), there seems to be very little if any direct evidence supporting either enhanced spontaneous AP generation in excitatory neurons or enhanced rates of sEPSCs arising from excitatory neurons (Zhang et al., 1999; Cunningham and Jones, 2001; van Brederode et al., 2001; but see Lambe and Aghajanian, 2001 and Zhou et al., 1999; Kopp-Scheinpflug et al., 2003). Finally, during our current-clamp experiments herein, we never observed any spontaneous APs in layer II/III pyramidal neurons across all of our recordings (data not shown), suggesting that spontaneous APs arising in these neurons are rather infrequent events.

Despite the paucity of either theory or experimental literature supporting a role for $\mathrm{K}_{\mathrm{v}} 1.1$ in regulating spontaneous AP-driven glutamatergic synaptic events, we assessed whether sEPSCs were altered at layer V pyramidal neurons in Disc1 mutant mice. To
A

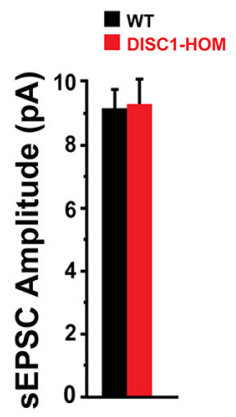

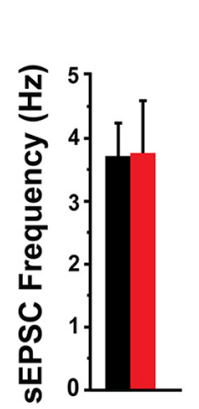

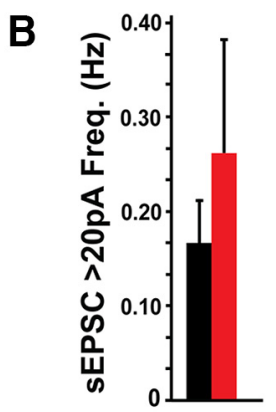

Figure 11. Spontaneous excitatory synaptic transmission detected at layer V pyramidal neurons is not altered in Disc 1 mutant mice. $A$, The amplitudes (left) of sEPSCs detected in layer $V$ pyramidal neurons were not altered in Disc 1 mutant mice ( $p=0.90$, unpaired $t$ test). The frequency (right) of $s E P S C s$ detected in layer $V$ pyramidal neurons was not altered in Disc1 mutant mice ( $p=0.96$, unpaired $t$ test). $\boldsymbol{B}$, The frequency of large-amplitude $\operatorname{EPSCS}(\geq 20 \mathrm{pA})$ was not altered in Disc 1 mutant mice ( $p=0.48$, unpaired $t$ test). Values represent the mean \pm SEM $(n / N=$ neurons $/$ mice: WT $=9 / 5 ;$ DISC1-HOM $=8 / 5)$.

address this possibility, we performed whole-cell recordings in layer $\mathrm{V}$ pyramidal neurons in acute brain slices and monitored spontaneous synaptic events at $-70 \mathrm{mV}$. We found that neither the frequency nor the amplitudes of sEPSCs were altered in Disc1 mutant mice (Fig. 11A; amplitude, $p=0.90$; frequency, $p=0.96$; unpaired $t$ tests). As AP-driven sEPSC could likely be reflected by larger synaptic events, we also assessed the frequency of sEPSCs that were $\geq 20 \mathrm{pA}$, which represented $\sim 5 \%$ of all sEPSC events detected. We found that even among this group of "largeamplitude" sEPSCs there was no statistically significant alteration in frequency in Disc1 mutant mice (Fig. 11B; $p=0.479$, unpaired $t$ test). Overall, these results assessing spontaneous glutamatergic transmission at layer $\mathrm{V}$ pyramidal neurons most likely indicate that the enhanced AP generation during current steps we observed in Disc1 mutant layer II/III pyramidal cells (Figs. 4, 7) does not additionally extend to hyperexcitability at the level of spontaneous AP generation in resting Discl mutant excitatory neurons.

\section{Reductions in $\mathrm{K}_{\mathrm{v}} 1.1$ functional expression are due to dysregulation of cAMP levels in Disc1 mutant mice}

Because reduced $\mathrm{K}_{\mathrm{v}} 1.1$ expression in Disc1 mutant mice suggested altered gene regulation (Fig. $6 D, E$ ), we investigated whether previously described alterations in cAMP levels and metabolism in Discl mutant mice might be in part responsible for these alterations in $\mathrm{K}_{\mathrm{v}} 1.1$ gene expression (Millar et al., 2007; Kvajo et al., 2011). Our previous analysis in the hippocampus of Disc1 mutant mice revealed a decrease in the protein levels and activity of PDE4 isoforms, as well as increased cAMP levels and phosphorylation of the key transcription factor CREB (Kvajo et al., 2011). CREB activity has been associated with the regulation of neuronal excitability through changes in the expression of sodium and potassium channels (Dong et al., 2006; Wallace et al., 2009). Thus, we investigated whether cAMP-mediated signaling may be underlying the observed channel expression phenotypes. Analysis of PDE4 protein levels revealed decreases in several PDE4 isoforms (Fig. 12C,E). Specifically, PDE4B1 and PDE4B3 were decreased $(p<0.05)$, whereas no difference was observed in PDE4A and PDE4D isoforms, indicating that this Discl mutation affects only selected PDE4s in the PFC (Fig. 12). As in the hippocampus, this decrease was not caused by alterations in transcription, because analysis of PDE4B transcripts by qRT-PCR revealed no genotypic difference (Fig. 12I). Consistent with the 
A

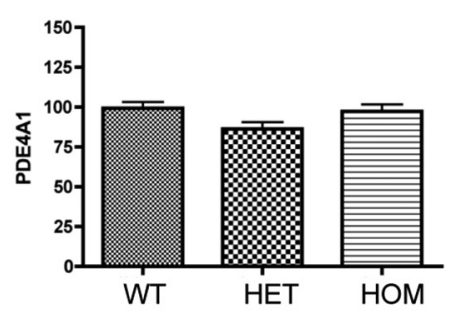

D

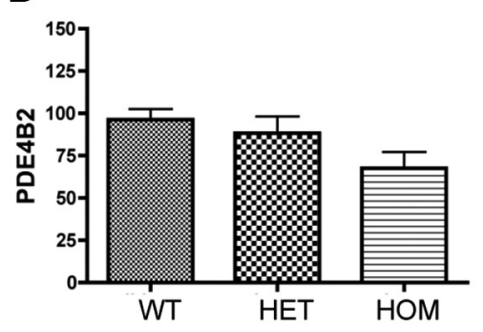

G

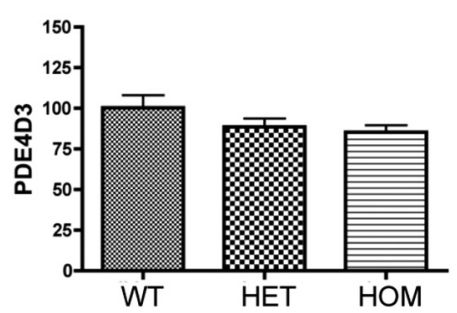

B

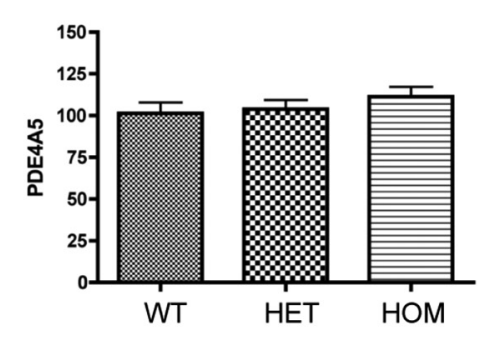

E

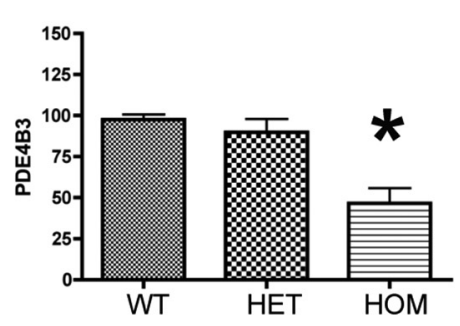

H

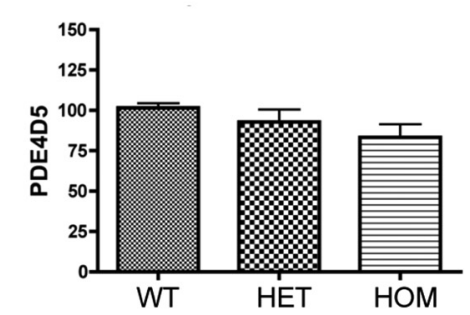

C

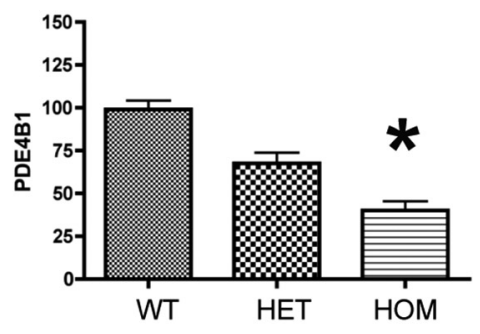

$F$

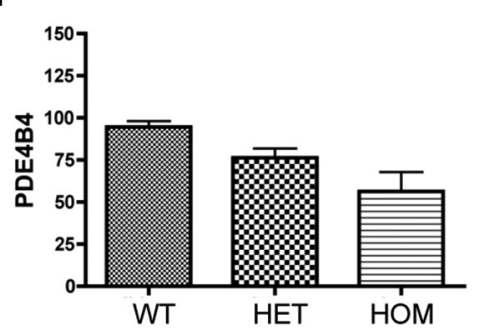

I

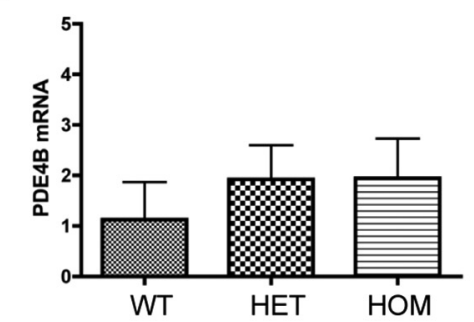

Figure 12. Disc1 mutant mice display evidence of decreased catabolism of CAMP by phosphodiesterase, PDE4, in the PFC. $\boldsymbol{A}, \boldsymbol{B}$, Analysis of PDE4A isoform protein levels in the PFC of Disc 1 mutant mice shows normal levels of PDE4A splice variants, PDE4A1 $(\boldsymbol{A})$, PDE4A5 $(\boldsymbol{B}) . p>0.05$, one-way ANOVA; $n=4 /$ genotype. Values are expressed as percentages of WT, mean \pm SEM. $\boldsymbol{C}-\boldsymbol{F}$, Analysis of PDE4B isoform protein levels shows decreased PDE4B1 $(\boldsymbol{C})$ and B3 $(\boldsymbol{E})$ variants $(p<0.05,1$-way ANOVA) in Disc1 mutant mice and normal levels of PDE4B2 $(\boldsymbol{D})$, and PDE4B4 $(\boldsymbol{F}) . n=4$ mice/genotype. $\boldsymbol{G}, \boldsymbol{H}$, Analysis of PDE4D isoform protein levels shows normal levels of PDE4D3 (G) and PDE4D5 $(\boldsymbol{H}) . p>0.05$, one-way ANOVA; $n=4 /$ genotype. $\boldsymbol{I}, 0$ bserved reductions in PDE4B protein levels are unlikely due to reducedPDE4B mRNA levels. PDE4B mRNA levels in the PFC by qRT-PCR. No difference among genotypes was observed $(n=3$ mice/genotype, $p>0.05$, one-way ANOVA). Summary data are the mean \pm SEM.

decrease in protein levels, the binding of rolipram, the prototypic PDE4 inhibitor, was also decreased in cortical extracts of Disc1 mutant mice (Fig. 13A). Reduced protein levels of PDE4 isoforms appeared physiologically significant as analysis of PDE4 activity in the PFC of Disc1 mutant mice revealed decreased activity, which reached significance in HOM mice $(p<0.05$; Fig. $13 B)$.

We further investigated whether changes in PDE4B activity alter cAMP levels in the PFC. Immunohistochemistry revealed an increase in cAMP immunoreactivity across the PFC, reaching significance in the superficial layers (Fig. 13C,D; $p<0.05$, twoway RM ANOVA).

Together, these results provide evidence consistent with altered cAMP metabolism leading to elevated levels of cAMP in the mPFC in Disc1 mutant mice. These results thus support the possibility that disruption of normal cAMP-dependent regulation of gene expression in Disc1 mutant mice could underlie the observed alterations in the functional expression of $\mathrm{K}_{\mathrm{v}} 1.1$ (Fig. 6).

\section{Pharmacological manipulations of cAMP metabolism in} cultured cortical neurons both rescue and mimic electrophysiological changes in mutant $\mathrm{MPFC}$ brain slices To more directly test whether alterations in cAMP metabolism in Disc1 mutant neurons were potentially in part responsible for the observed reduction in functional expression of voltagedependent potassium currents (Fig. 6), we used a neuronal cul- ture system that readily permitted prolonged pharmacological manipulation of cAMP metabolism. We first tested whether the cultured cortical neuron system recapitulated the enhanced excitability in Disc1 mutant neurons that we observed in the mPFC in acute brain slices of prefrontal cortex (Figs. 4A, B, 7B). Similar to what we observed in acute brain slices, whole-cell recordings in cultured neurons prepared from the prefrontal cortex revealed Disc1 mutant neurons showed enhanced excitability compared with cultured WT neurons, as evidenced by enhanced AP generation in response to injected current steps (Fig. $14 A, B ; p=$ 0.0044 , two-way RM ANOVA). The difference in excitability observed between genotypes was much more apparent in cultured neurons than in our assessment in mPFC brain slices, indicating that while enhanced excitability is present in Disc1 mutant neurons in both preparations, these very different preparations not surprisingly yielded quantitatively different results.

Although alterations in excitability and synaptic plasticity appeared to be largely explained by reductions in potassium channel function, it is worth noting that additional changes were observed that are suggestive of reduced functional expression of voltage-activated sodium channels (Fig. $6 A, B, D, 14 D$ ). Importantly, reductions in these currents were only significant in cultured neuronal studies (but not in acute slice studies) and furthermore would be unable to explain observed hyperexcitability in Disc1 mutant neurons. Thus, while these changes do not 
A

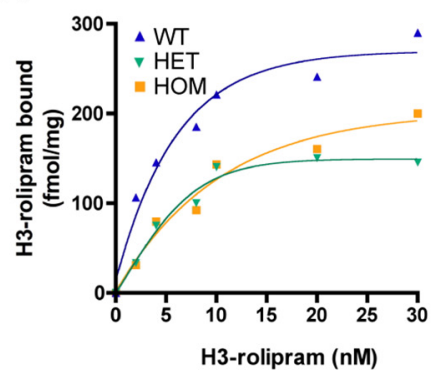

B

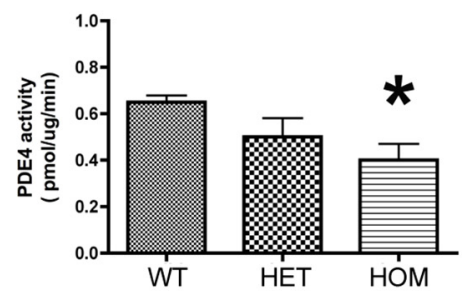

C
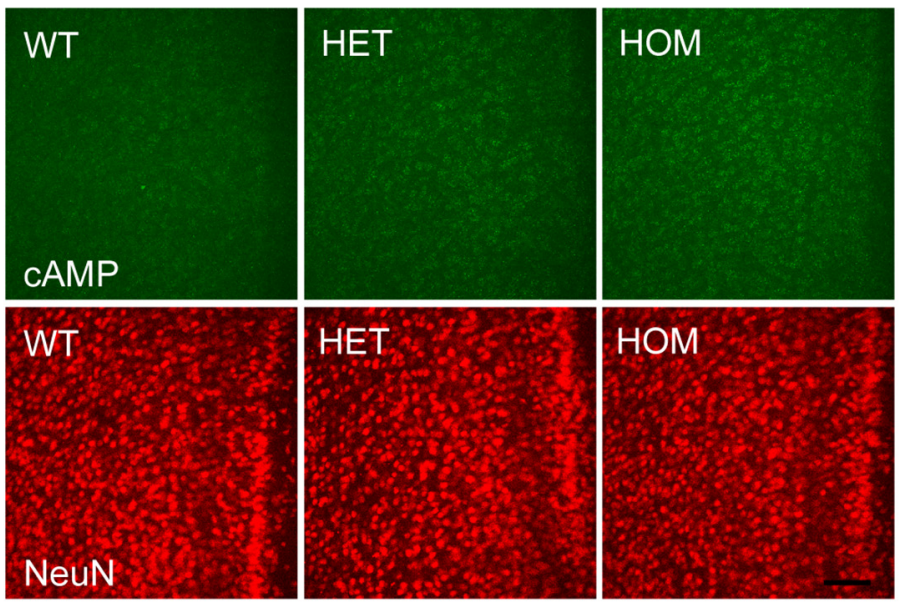

D

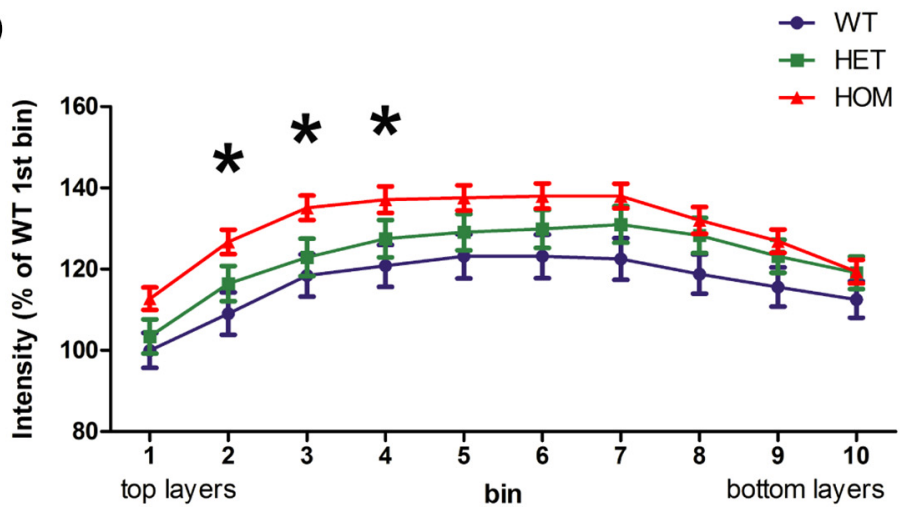

Figure 13. Disc1 mutant mice display increased CAMP in the PFC, suggesting decreased catabolism of cAMP. $\boldsymbol{A}$, Decreased rolipram binding in the PFC of Disc 1 mutant mice. Bmax values are decreased in HOM and HET mice $(n=7$ mice/genotype, $p<$ 0.05 , comparison of fits). Summary data (mean \pm SEM). $\boldsymbol{B}$, Decreased PDE4 activity in DISC-HOM mice (in picomoles/microgram/ minute; $p<0.05$, one-way ANOVA; $n=4$ mice/genotype). Summary data (mean \pm SEM). C, D, cAMP levels in the PFC, detected by immunohistochemistry. The neuronal marker NeuN is shown in red. D, Quantification of CAMP levels across the cortical layers. PFC images were divided into 10 equal bins, and CAMP intensity for each bin was calculated. Note the increase in cAMP in the superficial layers (bins 2-4, two-way RM ANOVA, post hoc analysis, $p<0.05$ ). Values are expressed as percentages of WT in the first bin. $n=3$ WT mice; $n=5$ HET mice; $n=5$ HOM mice. Scale bar, $100 \mu \mathrm{m}$. Values represent the mean \pm SEM.

seem causally related in any straightforward way to the alterations in neuronal excitability and synaptic plasticity we observed, it is possible that such changes could affect neuronal function in more subtle ways that were beyond the reach of our functional assays.

As Disc1 mutant mice demonstrate elevated cAMP levels in the PFC (Fig. 13C,D), we next tested whether the deficient voltage-dependent potassium currents observed in Disc1 mutants (Fig. $6 A, C$ ) could be restored by reducing cAMP production by incubating cultures with the adenylate cyclase blocker SQ (10 $\mu \mathrm{M}$, for $4-5 \mathrm{~d}$ beginning at DIV13). Consistent with results in acute brain slices (Fig. 6C), whole-cell recordings in control cultures treated with vehicle (DMSO) instead of SQ22536 revealed that Disc1 mutant neurons displayed reduced activation of voltagedependent potassium currents (Fig. $14 C, D ;-40 \mathrm{mV}$ step, $p=0.033 ; 0 \mathrm{mV}$ step, $p=0.045$, unpaired $t$ tests). Furthermore, while blockade of adenylate cyclase with SQ22536 did not enhance these potassium currents in WT neurons, in Disc1 mutant neurons SQ treatment significantly increased voltage-dependent potassium currents toward WT levels (Fig. 14C,D; WT-DMSO vs WT-SQ: -40 $\mathrm{mV}$ step, $p=0.45 ; 0 \mathrm{mV}$ step $p=0.35$; DISC1-HOM-DMSO vs DISC1-HOMSQ: $-40 \mathrm{mV}$ step, $p=0.035 ; 0 \mathrm{mV}$ step, $p=0.040$; unpaired $t$ tests). These results showing that prolonged adenylate cyclase blockade can rescue deficient voltagedependent potassium currents normally present in Discl mutant neurons suggests that alterations in the functional expression of these channels may result from the elevations in cAMP present in the prefrontal cortex of Discl mutant mice (Fig. $13 C, D)$.

To further explore the possible causal relationship between cAMP elevations and reductions in the functional expression of voltage-dependent potassium currents, we next investigated the effects of reducing phosphodiesterase activity upon these currents in WT neurons. As the elevated cAMP level present in Discl mutant neurons is thought to arise largely due to reduced function of PDE4 (likely due to the absence of a stabilizing Disc1-PDE4 interaction; Millar et al., 2007; Kvajo et al., 2011), we asked whether mimicking this scenario in WT neurons through pharmacological blockade of PDE4 with ROL ( $100 \mu \mathrm{M}$, for 4-5 d beginning at DIV13) could recapitulate the reductions in voltage-dependent potassium currents observed in Disc1 mutant neurons. In further support of a suppressive action of elevated cAMP upon the functional expression of these potassium currents, whole-cell recordings revealed that prolonged blockade of PDE4 with rolipram caused a significant reduction in voltage-dependent potassium currents in WT neurons compared with vehicle-treated WT neurons (Fig. $14 E, F ;-40 \mathrm{mV}$ step, $p=0.0023$; $0 \mathrm{mV}$ step, $p=$ 0.011 ). Together, results from experiments using pharmacological manipulations of cAMP metabolism support a mechanism whereby elevated levels of cAMP in Disc1 mutant neurons serve to suppress the functional expression of voltage-dependent potassium currents, most likely through alterations in cAMP-dependent gene regulation.

\section{Discussion}

The challenge of identifying deviant neural circuit patterns underlying psychiatric disorders is greatly facilitated by the discovery of rare 
A

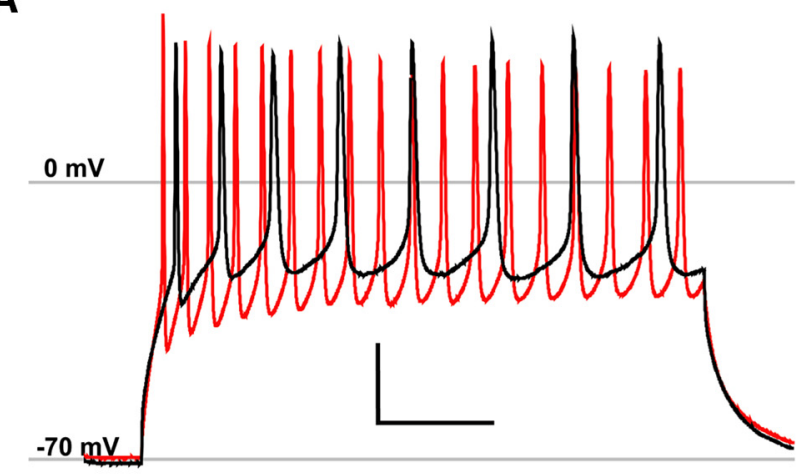

C

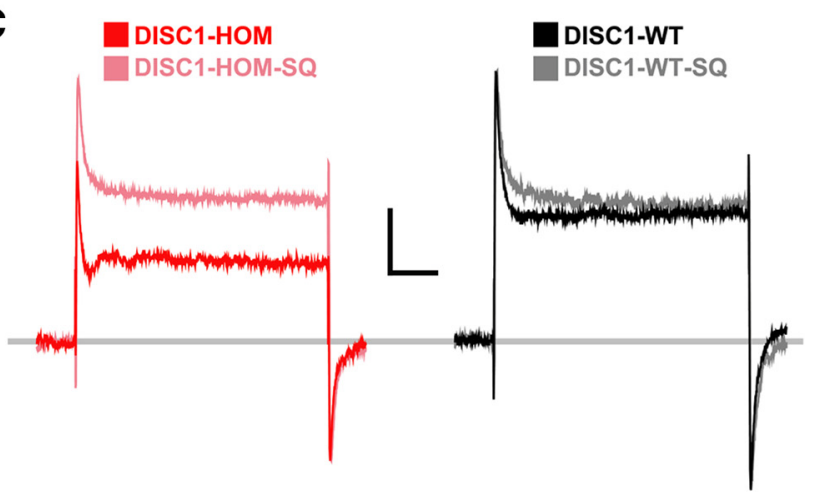

B

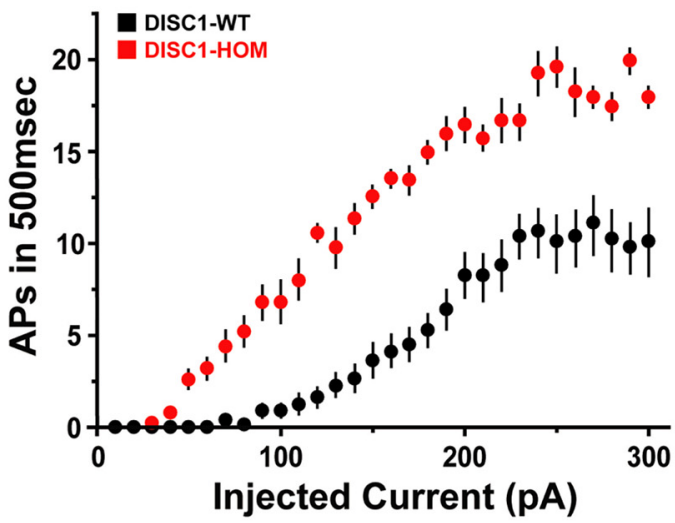

D

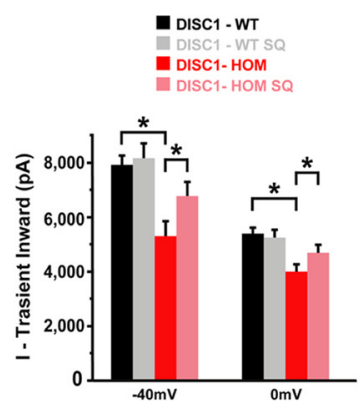

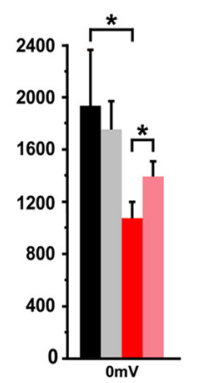

E

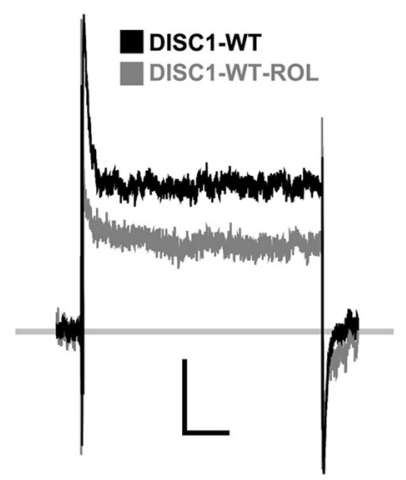

F

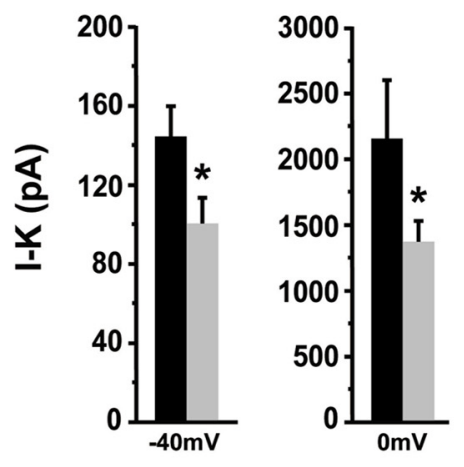

Figure 14. CAMP elevations in Disc1 mutant mice cause the observed reductions in near-threshold voltage-dependent potassium currents. $\boldsymbol{A}$, Cultured Disc1 mutant neurons display enhanced excitability (red trace) compared with WT neurons (black trace). Representative traces from current-clamp recordings from cultured prefrontal neurons showing near maximal AP responses to a 250 pA current step. Calibration: $20 \mathrm{mV}, 100 \mathrm{~ms}$. Reference levels, $V_{\text {rest }}=-70$ and $0 \mathrm{mV}$. B, Summary data (mean \pm SEM) of number of APs evoked by $500 \mathrm{~ms}$ current steps. WT recordings, black ( $n=$ 8); DISC1-HOM recordings, red ( $n=10$; two-way RM ANOVA, $p=0.0044)$. C, Reduced voltage-dependent potassium currents activated near AP threshold in Disc1 mutant neurons (red traces) are rescued with prolonged adenylyl cyclase blockade (pink traces). Representative traces from voltage-clamp recordings from cultured $P F C$ neurons showing activation of noninactivating potassium currents in response to a voltage step from -70 to $-40 \mathrm{mV}$ (near $\mathrm{V}_{\text {thresh }}$ ), in neurons treated with either SQ (10 $\mu \mathrm{M}$ ) or DMSO vehicle. DISC1-H0M (left traces; red DMSO, pink SQ) and WT mice (right traces; black DMSO, gray SQ). Calibration: $100 \mathrm{pA}, 20 \mathrm{~ms}$. Reference level, holding current at $\mathrm{V}_{\text {rest }}=-70 \mathrm{mV}$. For clarity of display, traces shown are in the presence of $500 \mathrm{~nm}$ TTX. $D$, Summary data (mean $\pm S E M)$ of peak transient inward currents $\left(\mathrm{I}_{\mathrm{T}}\right)$ and steady-state potassium currents $\left(\mathrm{I}_{\mathrm{K}}\right)$ evoked by voltage steps from $-70 \mathrm{mV}$ to indicated voltages. WT-DMSO $(n=25)$, black bars; WT-SQ $(n=21)$, gray bars; DISC1-HOM-DMSO $(n=19)$, red bars. DISC1-HOM-SQ $(n=21)$, red bars. NS, not significant [unpaired $t$ test: WT-DMSO vs DISC1-DMSO: $I_{\mathrm{K}}-40 \mathrm{mV}, p=0.033 ; I_{\mathrm{K}}, 0 \mathrm{mV}, p=$ $0.045 ; \mathrm{I}_{\mathrm{T},}, 40 \mathrm{mV}, p=0.00011 ; \mathrm{I}_{\mathrm{Tl}} 0 \mathrm{mV}, p=0.00015 ; \mathrm{WT}-\mathrm{DMSO} \mathrm{vs}$ WT-SQ: $\mathrm{I}_{\mathrm{K}},-40 \mathrm{mV}, p=0.45 ; \mathrm{I}_{\mathrm{K}}, 0 \mathrm{mV}, p=0.35$ (NS); $\mathrm{I}_{\mathrm{Tl}},-40 \mathrm{mV}, p=0.41$ (NS); $\mathrm{I}_{\mathrm{TI}} 0 \mathrm{mV}, p=0.38$ (NS); DISC1-DMSO vs DISC1-SQ: $\left.\mathrm{I}_{\mathrm{K}^{\prime}}-40 \mathrm{mV}, p=0.035 ; \mathrm{I}_{\mathrm{K}}, 0 \mathrm{mV}, p=0.040 ; \mathrm{I}_{\mathrm{T},},-40 \mathrm{mV}, p=0.031 ; \mathrm{I}_{\mathrm{T},}, 0 \mathrm{mV}, p=0.046\right]$. $\boldsymbol{E}$, Voltage-dependent potassium currents activated near AP threshold in WT neurons (black trace) are reduced upon prolonged PDE4 blockade (gray trace). Representative traces from voltage-clamp recordings showing activation of noninactivating potassium currents in response to a voltage step from -70 to $-40 \mathrm{mV}$ (near $\mathrm{V}_{\text {thresh }}$ ) in neurons treated with either ROL (100 $\mu \mathrm{m}$ ) or DMSO vehicle. Calibration: $100 \mathrm{pA}, 20 \mathrm{~ms}$. Reference level, holding current at $\mathrm{V}_{\text {rest }}=-70 \mathrm{mV}$. Traces shown are in the presence of $500 \mathrm{~nm}$ TTX. $\boldsymbol{F}$, Summary data (mean \pm SEM) of steady-state potassium currents evoked by voltage steps from -70 to indicated voltages. WT-DMSO ( $n=19)$, black bars; WT-ROL $(n=21)$. Unpaired $t$ test: WT-DMSO vs WT-ROL: $I_{k^{\prime}}-40 \mathrm{mV}, p=0.0023 ; I_{\mathrm{K}^{\prime}} 0 \mathrm{mV}, p=0.011$. Values represent the mean \pm SEM.

but highly penetrant genetic risk variants. Although these variants are individually responsible for only a very small percentage of cases, they are collectively very common and their high reliability to cause disease that is symptomatically indistinguishable from the majority of cases makes them invaluable tools in creating mouse models that faithfully recapitulate disease. Using such animal models in conjunc- tion with an integrated research strategy focusing on behavioral and cognitive domains that are known to be affected in SCZ and have well defined neural substrates can lead to more efficient identification of neural disease mechanisms that could be generalized over a variety of genetic causes (Xu et al., 2012; Crabtree and Gogos, 2014). In that context, this study evaluated how a bona fide pathogenic 
mutation that predisposes to SCZ and other major psychiatric disorders may affect the structure and function of cortical neural circuits. Analyses using morphological, proteomical, neurophysiological, biochemical, and cellular assays led to four main findings. First, we showed that Discl deficiency, in contrast to its effects in the hippocampus (Kvajo et al., 2008, 2011; Lepagnol-Bestel et al., 2013), was largely without detectable effect upon cortical architecture or neuronal cytoarchitecture at the resolution of our assays. Second, we provided evidence that afferent inputs synapsing onto layer $\mathrm{V}$ mPFC neurons in Disc1 mutant mice were hyperexcitable, arising in large part from decreased functional expression of the low-threshold, voltage-gated potassium channel subunit $\mathrm{K}_{\mathrm{v}} 1.1$. Third, we showed that synapses onto layer $\mathrm{V}$ neurons showed multiple functional alterations consistent with enhanced neurotransmitter release, leading to altered short-term synaptic plasticity. Changes in synaptic function were also substantially attributable to reduced functional expression of $\mathrm{K}_{\mathrm{v}} 1.1$ and plausibly linked to the AP widening observed in Disc1 mutant mice that would be expected to enhance $\mathrm{P}_{\mathrm{r}}$ through enhanced synaptic terminal $\mathrm{Ca}^{2+}$ influx during AP invasion. Fourth, similar to findings in the hippocampus (Kvajo et al., 2011), we found reduced activity and expression of PDE4 isoforms that led to elevated cAMP levels in the PFC of Discl mutant mice, which, in turn, contributed in part to the reduced functional expression of nearthreshold potassium currents in mutant mice.

The enhanced excitability in layer II/III pyramidal neurons can be substantially and specifically ascribed to decreased functional expression of voltage-dependent potassium currents mediated by $\mathrm{K}_{\mathrm{v}}$ 1.1-containing channels (Robertson et al., 1996; Simeon et al., 2013, 2014; Bagchi et al., 2014). Low-voltage activated potassium channels composed of $\mathrm{K}_{\mathrm{v}} 1$ family member subunits show significant activation near the action potential threshold voltage (Bekkers and Delaney, 2001). Their activation in this voltage range leads to a hyperpolarizing current that impedes action potential generation, thus serving to reduce neuronal excitability in neurons, including pyramidal neurons of the neocortex and hippocampus (Bekkers and Delaney, 2001; Dodson et al., 2002; Goldberg et al., 2008). Notably, the $\mathrm{K}_{\mathrm{v}} 1.1$-null mouse displays severe seizures, enhanced neuronal excitability, and reduced low-threshold potassium currents (Smart et al., 1998; Brew et al., 2003). Given the important role of $\mathrm{K}_{\mathrm{v}} 1$ channels in regulating excitability, it is likely that the observed alterations in $\mathrm{K}_{\mathrm{v}} 1.1$ function would lead to significant disruption of neural circuits and contribute to SCZ symptomology.

While diverse mechanisms can lead to alterations in shortterm synaptic plasticity similar to those observed here (Rose and Konnerth, 2001; Catterall and Few, 2008), our expression analysis indicating selective reduction in $\mathrm{K}_{\mathrm{v}} 1.1$, our pharmacological blockade of $\mathrm{K}_{\mathrm{v}}$ 1.1-containing channels and a series of control experiments addressing the contribution of alternative cellular mechanisms suggest that the alterations in short-term synaptic plasticity we observed can be substantially and proximately attributed to reduced function of $\mathrm{K}_{\mathrm{v}} 1$.1-containing channels in Disc1 mutant excitatory neurons (Robertson et al., 1996; Simeon et al., 2013, 2014; Bagchi et al., 2014). Potassium channels localized to presynaptic terminals play a variety of important roles, including the modulation of neurotransmitter release (Dodson and Forsythe, 2004). In addition to effects upon excitability, reduced expression, inactivation, or blockade of various $\mathrm{K}_{\mathrm{v}}$ channels_-including $\mathrm{K}_{\mathrm{v}} 1.1$ and other $\mathrm{K}_{\mathrm{v}} 1$ family members — can lead to action potential widening, which facilitates neurotransmitter release through the enhanced $\mathrm{AP}$-evoked $\mathrm{Ca}^{2+}$ influx resulting from prolonged depolarization of presynaptic terminals (Borst and Sakmann, 1999; Geiger and Jonas, 2000; Guan et al., 2007;
Kole et al., 2007). Furthermore, even modest changes in action potential width can have a dramatic impact on the amplitude of synaptic events due to the steep, supralinear relationship between $\mathrm{Ca}^{2+}$ influx and neurotransmitter release (Borst and Sakmann, 1999). $K_{v} 1$ family channels including $K_{v} 1.1$ are present in presynaptic terminals, and reductions in their function lead to AP widening and enhanced neurotransmitter release (Wang et al., 1994; Southan and Robertson, 1998b; Kole et al., 2007). AP widening thus leads to increased presynaptic initial probability of release shifting presynaptic short-term plasticity toward depression, altering synaptic computation and neural circuit function (Abbott and Regehr, 2004). Furthermore, our observation that differences in STD were most apparent at lower stimulation frequencies is supportive of our proposed role of action potential widening. It is well established that during trains, action potentials normally broaden with successive spikes-due to use-dependent reductions in function of diverse potassium channels - becoming maximal at higher stimulus frequencies (Aldrich et al., 1979; Geiger and Jonas, 2000; Bean, 2007). Thus, the observed genotype differences in baseline AP width would likely lead to the greatest differences in neurotransmitter release at the lowest stimulus frequencies, while their impact would be minimized at higher stimulus frequencies, during which multiple additional mechanisms are recruited to broaden APs in both genotypes (Aldrich et al., 1979; Connors et al., 1982; Ma and Koester, 1995, 1996; Zhou and Hablitz, 1996; Geiger and Jonas, 2000; Bean, 2007; Deng et al., 2013).

Our findings provide enlightenment concerning PFC involvement in working memory deficits, the most prominent cognitive deficit described in this Disc1 mutant strain, and are also important for extracting general principles about the nature of the neural activity changes elicited by SCZ-risk mutations. Indeed, genomic studies of neuropsychiatric disease identified a large and diverse array of risk genes. Yet, despite this genetic diversity, evidence of functional convergence points to neural circuits and specifically the disruption of stable dynamics of intricately connected neuronal ensembles (Crabtree and Gogos, 2014). Importantly, there is accumulating evidence in diverse mouse models of SCZ suggesting a potentially pervasive role of short-term plasticity alterations, supporting that such changes in synaptic computation may fundamentally contribute to the profound deficits in short-term information processing in SCZ (Arguello and Gogos, 2012; Crabtree and Gogos, 2014) and possibly other psychiatric disorders. Here our results provide further support for this concept and reveal a novel underlying mechanism. These dysfunctions in prefrontal short-term plasticity may contribute to cognitive deficits as well as other PFC-dependent symptoms of SCZ and other psychiatric disorders (e.g., major depression) associated with the DISC1 translocation.

Our findings in the PFC of reduced levels and function of PDE4 isoforms and increased cAMP levels suggest that elevated cAMP levels in the Disc1 mutant PFC might play a causal role in the changes in functional expression of $\mathrm{K}_{\mathrm{v}} 1.1$. Furthermore, that alterations in voltage-dependent potassium currents could be mimicked (PDE4 blockade) or rescued (adenylyl cyclase blockade) with prolonged pharmacological manipulations of cAMP metabolic pathways supports such a causality. It should be noted, however, that while cortical alterations of cAMP levels could lead in principle to diverse alterations in neuronal function (Benito and Barco, 2010; Kandel, 2012; Sanderson and Sher, 2013; He et al., 2014), the observed increase in cAMP levels were modest and largely restricted to the superficial cortical layers suggesting that changes in cAMP-dependent gene expression are expected to be regional and limited to targets that are particularly sensitive to 
cAMP levels. In this regard, it is notable that among the five candidate voltage-gated potassium channel subunits we evaluated only $\mathrm{K}_{\mathrm{v}} 1.1$ showed altered expression, suggesting the possibility that the $\mathrm{K}_{\mathrm{v}} 1.1$ locus may have a particularly low threshold for cAMP-dependent regulation. Indeed, our proteomics analysis as well as results from gene expression in the hippocampus (unpublished data) argue against widespread changes in cAMPdependent transcription. Given these considerations, it is important to note that there is strong evidence that potassium channel expression is regulated both through cAMP signaling and CREBmediated transcription (Allen et al., 1998; McClung and Nestler, 2003; Dong et al., 2006; Wallace et al., 2009). As such, based upon the correlation of results of mRNA expression and electrophysiological assays using manipulations of neuronal cAMP levels, the reductions in voltage-dependent potassium currents we observed in Disc1 mutant mice seem most likely to be attributable to alterations in cAMP-dependent expression of $\mathrm{K}_{\mathrm{v}} 1.1$. Interestingly, however, cAMP can also indirectly modulate potassium channel activation through its regulation of PKA-dependent phosphorylation (Winklhofer et al., 2003), suggesting that increased cAMP levels in Discl mutant mice could affect different aspects of potassium channel function through multiple routes of action. Regarding the mechanistic basis of cAMP increase, we have previously shown that that DISC1 consistently localizes to vesicles associated with the trans-Golgi network (Lepagnol-Bestel et al., 2013). PDE4D, a major regulator of cAMP levels that is decreased in Disc1 mutant mice, is also associated with the Golgi apparatus (Verde et al., 2001). Thus, DISC1 may be part of macromolecular complexes regulating cAMP in this perinuclear cellular compartment.

Our findings point toward one explanation for the strong link between DISC1 deficiency and psychiatric illness as they reveal a potentially powerful disease mechanism in the PFC whereby dysregulation of a single target of DISC1 deficiency can disrupt multiple encoding mechanisms along a neural circuit leading to cumulative dysfunction.

\section{References}

Abbott LF, Regehr WG (2004) Synaptic computation. Nature 431:796-803. CrossRef Medline

Aldrich RW Jr, Getting PA, Thompson SH (1979) Mechanism of frequencydependent broadening of molluscan neurone soma spikes. J Physiol 291: 531-544. CrossRef Medline

Allen ML, Koh DS, Tempel BL (1998) Cyclic AMP regulates potassium channel expression in C6 glioma by destabilizing Kv1.1 mRNA. Proc Natl Acad Sci U S A 95:7693-7698. CrossRef Medline

Arguello PA, Gogos JA (2010) Cognition in mouse models of schizophrenia susceptibility genes. Schizophr Bull 36:289-300. CrossRef Medline

Arguello PA, Gogos JA (2012) Genetic and cognitive windows into circuit mechanisms of psychiatric disease. Trends Neurosci 35:3-13. CrossRef Medline

Bagchi B, Al-Sabi A, Kaza S, Scholz D, O’Leary VB, Dolly JO, Ovsepian SV (2014) Disruption of myelin leads to ectopic expression of K(V)1.1 channels with abnormal conductivity of optic nerve axons in a cuprizoneinduced model of demyelination. PLoS One 9:e87736. CrossRef Medline

Bean BP (2007) The action potential in mammalian central neurons. Nat Rev Neurosci 8:451-465. CrossRef Medline

Begum R, Bakiri Y, Volynski KE, Kullmann DM (2016) Action potential broadening in a presynaptic channelopathy. Nat Commun 7:12102. CrossRef Medline

Bekkers JM, Delaney AJ (2001) Modulation of excitability by alphadendrotoxin-sensitive potassium channels in neocortical pyramidal neurons. J Neurosci 21:6553-6560. Medline

Benito E, Barco A (2010) CREB's control of intrinsic and synaptic plasticity: implications for CREB-dependent memory models. Trends Neurosci 33: 230-240. CrossRef Medline

Benjamini Y, Hochberg Y (1995) Controlling the false discovery rate: a practical and powerful approach to multiple testing. J R Stat Soc Series B Stat Methodol 57:289-300.

Borst JG, Sakmann B (1999) Effect of changes in action potential shape on calcium currents and transmitter release in a calyx-type synapse of the rat auditory brainstem. Philos Trans R Soc Lond B Biol Sci 354:347-355. CrossRef Medline

Bradshaw NJ, Porteous DJ (2012) DISC1-binding proteins in neural development, signalling and schizophrenia. Neuropharmacology 62:12301241. CrossRef Medline

Brenowitz S, David J, Trussell L (1998) Enhancement of synaptic efficacy by presynaptic GABA(B) receptors. Neuron 20:135-141. CrossRef Medline

Brew HM, Hallows JL, Tempel BL (2003) Hyperexcitability and reduced low threshold potassium currents in auditory neurons of mice lacking the channel subunit Kv1.1. J Physiol 548:1-20. CrossRef Medline

Catterall WA, Few AP (2008) Calcium channel regulation and presynaptic plasticity. Neuron 59:882-901. CrossRef Medline

Chang CY, Picotti P, Hüttenhain R, Heinzelmann-Schwarz V, Jovanovic M, Aebersold R, Vitek O (2012) Protein significance analysis in selected reaction monitoring (SRM) measurements. Mol Cell Proteomics 11: M111.014662. CrossRef Medline

Clapcote SJ, Lipina TV, Millar JK, Mackie S, Christie S, Ogawa F, Lerch JP, Trimble K, Uchiyama M, Sakuraba Y, Kaneda H, Shiroishi T, Houslay MD, Henkelman RM, Sled JG, Gondo Y, Porteous DJ, Roder JC (2007) Behavioral phenotypes of Disc1 missense mutations in mice. Neuron 54:387-402. CrossRef Medline

Connors BW, Gutnick MJ, Prince DA (1982) Electrophysiological properties of neocortical neurons in vitro. J Neurophysiol 48:1302-1320. Medline

Crabtree GW, Gogos JA (2014) Synaptic plasticity, neural circuits, and the emerging role of altered short-term information processing in schizophrenia. Front Synaptic Neurosci 6:28. CrossRef Medline

Cunningham MO, Jones RS (2001) Dendrotoxin sensitive potassium channels modulate GABA but not glutamate release in the rat entorhinal cortex in vitro. Neuroscience 107:395-404. CrossRef Medline

Davies CH, Davies SN, Collingridge GL (1990) Paired-pulse depression of monosynaptic GABA-mediated inhibitory postsynaptic responses in rat hippocampus. J Physiol 424:513-531. CrossRef Medline

Deng PY, Rotman Z, Blundon JA, Cho Y, Cui J, Cavalli V, Zakharenko SS, Klyachko VA (2013) FMRP regulates neurotransmitter release and synaptic information transmission by modulating action potential duration via BK channels. Neuron 77:696-711. CrossRef Medline

Dodson PD, Forsythe ID (2004) Presynaptic K+ channels: electrifying regulators of synaptic terminal excitability. Trends Neurosci 27:210-217. CrossRef Medline

Dodson PD, Barker MC, Forsythe ID (2002) Two heteromeric $\mathrm{K}_{\mathrm{v}} 1$ potassium channels differentially regulate action potential firing. J Neurosci 22:6953-6961. Medline

Dong Y, Green T, Saal D, Marie H, Neve R, Nestler EJ, Malenka RC (2006) CREB modulates excitability of nucleus accumbens neurons. Nat Neurosci 9:475-477. CrossRef Medline

Duan X, Chang JH, Ge S, Faulkner RL, Kim JY, Kitabatake Y, Liu XB, Yang CH, Jordan JD, Ma DK, Liu CY, Ganesan S, Cheng HJ, Ming GL, Lu B, Song H (2007) Disrupted-In-Schizophrenia 1 regulates integration of newly generated neurons in the adult brain. Cell 130:1146-1158. CrossRef Medline

Dutar P, Nicoll RA (1988) Pre- and postsynaptic GABAB receptors in the hippocampus have different pharmacological properties. Neuron 1:585591. Medline

Ernst A, Ma D, Garcia-Perez I, Tsang TM, Kluge W, Schwarz E, Guest PC, Holmes E, Sarnyai Z, Bahn S (2012) Molecular validation of the acute phencyclidine rat model for schizophrenia: identification of translational changes in energy metabolism and neurotransmission. J Proteome Res 11:3704-3714. CrossRef Medline

Fénelon K, Mukai J, Xu B, Hsu PK, Drew LJ, Karayiorgou M, Fischbach GD, Macdermott AB, Gogos JA (2011) Deficiency of Dgcr8, a gene disrupted by the 22q11.2 microdeletion, results in altered short-term plasticity in the prefrontal cortex. Proc Natl Acad Sci U S A 108:4447-4452. CrossRef Medline

Fénelon K, Xu B, Lai CS, Mukai J, Markx S, Stark KL, Hsu PK, Gan WB, Fischbach GD, MacDermott AB, Karayiorgou M, Gogos JA (2013) The pattern of cortical dysfunction in a mouse model of a schizophreniarelated microdeletion. J Neurosci 33:14825-14839. CrossRef Medline

Geiger JR, Jonas P (2000) Dynamic control of presynaptic Ca(2+) inflow by 
fast-inactivating $\mathrm{K}(+)$ channels in hippocampal mossy fiber boutons. Neuron 28:927-939. CrossRef Medline

Gittelman JX, Tempel BL (2006) Kv1.1-containing channels are critical for temporal precision during spike initiation. J Neurophysiol 96:1203-1214. CrossRef Medline

Glazebrook PA, Ramirez AN, Schild JH, Shieh CC, Doan T, Wible BA, Kunze DL (2002) Potassium channels Kv1.1, Kv1.2 and Kv1.6 influence excitability of rat visceral sensory neurons. J Physiol 541:467-482. CrossRef Medline

Goldberg EM, Clark BD, Zagha E, Nahmani M, Erisir A, Rudy B (2008) K+ channels at the axon initial segment dampen near-threshold excitability of neocortical fast-spiking GABAergic interneurons. Neuron 58:387-400. CrossRef Medline

Goldman-Rakic PS (1995) Architecture of the prefrontal cortex and the central executive. Ann N Y Acad Sci 769:71-83. CrossRef Medline

Goshima Y, Nakamura F, Strittmatter P, Strittmatter SM (1995) Collapsininduced growth cone collapse mediated by an intracellular protein related to UNC-33. Nature 376:509-514. CrossRef Medline

Grissmer S, Nguyen AN, Aiyar J, Hanson DC, Mather RJ, Gutman GA, Karmilowicz MJ, Auperin DD, Chandy KG (1994) Pharmacological characterization of five cloned voltage-gated $\mathrm{K}+$ channels, types Kv1.1, $1.2,1.3,1.5$, and 3.1 , stably expressed in mammalian cell lines. Mol Pharmacol 45:1227-1234. Medline

Guan D, Lee JC, Higgs MH, Spain WJ, Foehring RC (2007) Functional roles of Kv1 channels in neocortical pyramidal neurons. J Neurophysiol 97: 1931-1940. CrossRef Medline

He C, Chen F, Li B, Hu Z (2014) Neurophysiology of HCN channels: from cellular functions to multiple regulations. Prog Neurobiol 112:1-23. CrossRef Medline

Herson PS, Virk M, Rustay NR, Bond CT, Crabbe JC, Adelman JP, Maylie J (2003) A mouse model of episodic ataxia type-1. Nat Neurosci 6:378383. CrossRef Medline

Hikida T, Jaaro-Peled H, Seshadri S, Oishi K, Hookway C, Kong S, Wu D, Xue R, Andradé M, Tankou S, Mori S, Gallagher M, Ishizuka K, Pletnikov M, Kida S, Sawa A (2007) Dominant-negative DISC1 transgenic mice display schizophrenia-associated phenotypes detected by measures translatable to humans. Proc Natl Acad Sci U S A 104:14501-14506. CrossRef Medline

Kandel ER (2012) The molecular biology of memory: cAMP, PKA, CRE, CREB-1, CREB-2, and CPEB. Mol Brain 5:14. CrossRef Medline

Koike H, Arguello PA, Kvajo M, Karayiorgou M, Gogos JA (2006) Disc1 is mutated in the 129S6/SvEv strain and modulates working memory in mice. Proc Natl Acad Sci U S A 103:3693-3697. CrossRef Medline

Kole MH, Letzkus JJ, Stuart GJ (2007) Axon initial segment Kv1 channels control axonal action potential waveform and synaptic efficacy. Neuron 55:633-647. CrossRef Medline

Kopp-Scheinpflug C, Fuchs K, Lippe WR, Tempel BL, Rübsamen R (2003) Decreased temporal precision of auditory signaling in Kcna1-null mice: an electrophysiological study in vivo. J Neurosci 23:9199-9207. Medline

Krishnamurthy D, Harris LW, Levin Y, Koutroukides TA, Rahmoune H, Pietsch S, Vanattou-Saifoudine N, Leweke FM, Guest PC, Bahn S (2013) Metabolic, hormonal and stress-related molecular changes in postmortem pituitary glands from schizophrenia subjects. World J Biol Psychiatry 14:478-489. CrossRef Medline

Kuroda K, Yamada S, Tanaka M, Iizuka M, Yano H, Mori D, Tsuboi D, Nishioka T, Namba T, lizuka Y, Kubota S, Nagai T, Ibi D, Wang R, Enomoto A, Isotani-Sakakibara M, Asai N, Kimura K, Kiyonari H, Abe T, et al (2011) Behavioral alterations associated with targeted disruption of exons 2 and 3 of the Discl gene in the mouse. Hum Mol Genet 20:46664683. CrossRef Medline

Kvajo M, McKellar H, Arguello PA, Drew LJ, Moore H, MacDermott AB, Karayiorgou M, Gogos JA (2008) A mutation in mouse Discl that models a schizophrenia risk allele leads to specific alterations in neuronal architecture and cognition. Proc Natl Acad Sci U S A 105:7076-7081. CrossRef Medline

Kvajo M, McKellar H, Gogos JA (2010) Molecules, signaling, and schizophrenia. Curr Top Behav Neurosci 4:629-656. CrossRef Medline

Kvajo M, McKellar H, Drew LJ, Lepagnol-Bestel AM, Xiao L, Levy RJ, Blazeski R, Arguello PA, Lacefield CO, Mason CA, Simonneau M, O'Donnell JM, MacDermott AB, Karayiorgou M, Gogos JA (2011) Altered axonal targeting and short-term plasticity in the hippocampus of Discl mutant mice. Proc Natl Acad Sci U S A 108:E1349-E1358. CrossRef Medline
Lai WS, Xu B, Westphal KG, Paterlini M, Olivier B, Pavlidis P, Karayiorgou M, Gogos JA (2006) Akt1 deficiency affects neuronal morphology and predisposes to abnormalities in prefrontal cortex functioning. Proc Natl Acad Sci U S A 103:16906-16911. CrossRef Medline

Lambe EK, Aghajanian GK (2001) The role of $\mathrm{K}_{\mathrm{v}} 1.2$-containing potassium channels in serotonin-induced glutamate release from thalamocortical terminals in rat frontal cortex. J Neurosci 21:9955-9963. Medline

Lepagnol-Bestel AM, Kvajo M, Karayiorgou M, Simonneau M, Gogos JA (2013) A Disc1 mutation differentially affects neurites and spines in hippocampal and cortical neurons. Mol Cell Neurosci 54:84-92. CrossRef Medline

Li KX, Lu YM, Xu ZH, Zhang J, Zhu JM, Zhang JM, Cao SX, Chen XJ, Chen Z, Luo JH, Duan S, Li XM (2011) Neuregulin 1 regulates excitability of fast-spiking neurons through Kv1.1 and acts in epilepsy. Nat Neurosci 15:267-273. CrossRef Medline

Ma M, Koester J (1995) Consequences and mechanisms of spike broadening of R20 cells in Aplysia californica. J Neurosci 15:6720-6734. Medline

Ma M, Koester J (1996) The role of K+ currents in frequency-dependent spike broadening in Aplysia R20 neurons: a dynamic-clamp analysis. J Neurosci 16:4089-4101. Medline

Madison DV, Nicoll RA (1984) Control of the repetitive discharge of rat CA 1 pyramidal neurones in vitro. J Physiol 354:319-331. CrossRef Medline Martins-de-Souza D, Martins D, Menezes de Oliveira B, dos Santos Farias A, Horiuchi RS, Crepaldi Domingues C, de Paula E, Marangoni S, Gattaz WF, Dias-Neto E, Camillo Novello J (2007) The use of ASB-14 in combination with CHAPS is the best for solubilization of human brain proteins for two-dimensional gel electrophoresis. Brief Funct Genomic Proteomic 6:70-75. CrossRef Medline

Martins-de-Souza D, Alsaif M, Ernst A, Harris LW, Aerts N, Lenaerts I, Peeters PJ, Amess B, Rahmoune H, Bahn S, Guest PC (2012) The application of selective reaction monitoring confirms dysregulation of glycolysis in a preclinical model of schizophrenia. BMC Res Notes 5:146. CrossRef Medline

McClung CA, Nestler EJ (2003) Regulation of gene expression and cocaine reward by CREB and DeltaFosB. Nat Neurosci 6:1208-1215. CrossRef Medline

Millar JK, Mackie S, Clapcote SJ, Murdoch H, Pickard BS, Christie S, Muir WJ, Blackwood DH, Roder JC, Houslay MD, Porteous DJ (2007) Disrupted in schizophrenia 1 and phosphodiesterase 4B: towards an understanding of psychiatric illness. J Physiol 584:401-405. CrossRef Medline

Miller EK, Cohen JD (2001) An integrative theory of prefrontal cortex function. Annu Rev Neurosci 24:167-202. CrossRef Medline

Miller EK, Erickson CA, Desimone R (1996) Neural mechanisms of visual working memory in prefrontal cortex of the macaque. J Neurosci 16: 5154-5167. Medline

Minturn JE, Fryer HJ, Geschwind DH, Hockfield S (1995) TOAD-64, a gene expressed early in neuronal differentiation in the rat, is related to unc-33, a C. elegans gene involved in axon outgrowth. J Neurosci 15:6757-6766. Medline

Mitchell KJ (2012) What is complex about complex disorders? Genome Biol 13:237. CrossRef Medline

Park SJ, Jeong J, Park YU, Park KS, Lee H, Lee N, Kim SM, Kuroda K, Nguyen MD, Kaibuchi K, Park SK (2015) Disrupted-in-schizophrenia-1 (DISC1) regulates endoplasmic reticulum calcium dynamics. Sci Rep 5:8694. CrossRef Medline

Picotti P, Aebersold R (2012) Selected reaction monitoring-based proteomics: workflows, potential, pitfalls and future directions. Nat Methods 9:555-566. CrossRef Medline

R Development Core Team (2013) R: A language and environment for statistical computing. Vienna, Austria: R Project for Statistical Computing.

Robertson B, Owen D, Stow J, Butler C, Newland C (1996) Novel effects of dendrotoxin homologues on subtypes of mammalian Kv1 potassium channels expressed in Xenopus oocytes. FEBS Lett 383:26-30. CrossRef Medline

Rodriguez-Murillo L, Gogos JA, Karayiorgou M (2012) The genetic architecture of schizophrenia: new mutations and emerging paradigms. Annu Rev Med 63:63-80. CrossRef Medline

Rose CR, Konnerth A (2001) Stores not just for storage. intracellular calcium release and synaptic plasticity. Neuron 31:519-522. CrossRef Medline

Sanderson TM, Sher E (2013) The role of phosphodiesterases in hippocampal synaptic plasticity. Neuropharmacology 74:86-95. CrossRef Medline Serafini T, Orci L, Amherdt M, Brunner M, Kahn RA, Rothman JE (1991) 
ADP-ribosylation factor is a subunit of the coat of Golgi-derived COPcoated vesicles: a novel role for a GTP-binding protein. Cell 67:239-253. CrossRef Medline

Simeone TA, Simeone KA, Samson KK, Kim DY, Rho JM (2013) Loss of the Kv1.1 potassium channel promotes pathologic sharp waves and high frequency oscillations in in vitro hippocampal slices. Neurobiol Dis 54:6881. CrossRef Medline

Simeone TA, Samson KK, Matthews SA, Simeone KA (2014) In vivo ketogenic diet treatment attenuates pathologic sharp waves and high frequency oscillations in in vitro hippocampal slices from epileptic Kv $1.1 \alpha$ knockout mice. Epilepsia 55:e44-e49. CrossRef Medline

Smart SL, Lopantsev V, Zhang CL, Robbins CA, Wang H, Chiu SY, Schwartzkroin PA, Messing A, Tempel BL (1998) Deletion of the K(V)1.1 potassium channel causes epilepsy in mice. Neuron 20:809-819. CrossRef Medline

Southan AP, Robertson B (1998a) Patch-clamp recordings from cerebellar basket cell bodies and their presynaptic terminals reveal an asymmetric distribution of voltage-gated potassium channels. J Neurosci 18:948-955. Medline

Southan AP, Robertson B (1998b) Modulation of inhibitory post-synaptic currents (IPSCs) in mouse cerebellar Purkinje and basket cells by snake and scorpion toxin K+ channel blockers. Br J Pharmacol 125:1375-1381. CrossRef Medline

Storey JD (2003) The positive false discovery rate: a Bayesian interpretation and the q-value. Ann Stat 31:2013-2035. CrossRef

Surinova S, Hüttenhain R, Chang CY, Espona L, Vitek O, Aebersold R (2013) Automated selected reaction monitoring data analysis workflow for largescale targeted proteomic studies. Nat Protoc 8:1602-1619. CrossRef Medline

Tan YP, Llano I (1999) Modulation by K+ channels of action potentialevoked intracellular $\mathrm{Ca} 2+$ concentration rises in rat cerebellar basket cell axons. J Physiol 520:65-78. CrossRef Medline

Tang W, Thevathasan JV, Lin Q, Lim KB, Kuroda K, Kaibuchi K, Bilger M, Soong TW, Fivaz M (2016) Stimulation of synaptic vesicle exocytosis by the mental disease gene DISC1 is mediated by N-type voltage-gated calcium channels. Front Synaptic Neurosci 8:15. CrossRef Medline

Tsuboi D, Kuroda K, Tanaka M, Namba T, Iizuka Y, Taya S, Shinoda T, Hikita T, Muraoka S, Iizuka M, Nimura A, Mizoguchi A, Shiina N, Sokabe M, Okano H, Mikoshiba K, Kaibuchi K (2015) Disrupted-in-schizophrenia 1 regulates transport of ITPR1 mRNA for synaptic plasticity. Nat Neurosci 18:698-707. CrossRef Medline

Uhlhaas PJ, Singer W (2010) Abnormal neural oscillations and synchrony in schizophrenia. Nat Rev Neurosci 11:100-113. CrossRef Medline

van Brederode JF, Rho JM, Cerne R, Tempel BL, Spain WJ (2001) Evidence of altered inhibition in layer $\mathrm{V}$ pyramidal neurons from neocortex of Kcna1-null mice. Neuroscience 103:921-929. CrossRef Medline

Vandenberg RJ, Ryan RM (2013) Mechanisms of glutamate transport. Physiol Rev 93:1621-1657. CrossRef Medline
Verde I, Pahlke G, Salanova M, Zhang G, Wang S, Coletti D, Onuffer J, Jin SL, Conti M (2001) Myomegalin is a novel protein of the golgi/centrosome that interacts with a cyclic nucleotide phosphodiesterase. J Biol Chem 276:11189-11198. CrossRef Medline

Volianskis A, Jensen MS (2003) Transient and sustained types of long-term potentiation in the CA1 area of the rat hippocampus. J Physiol 550:459492. CrossRef Medline

Wallace DL, Han MH, Graham DL, Green TA, Vialou V, Iñiguez SD, Cao JL, Kirk A, Chakravarty S, Kumar A, Krishnan V, Neve RL, Cooper DC, Bolaños CA, Barrot M, McClung CA, Nestler EJ (2009) CREB regulation of nucleus accumbens excitability mediates social isolation-induced behavioral deficits. Nat Neurosci 12:200-209. CrossRef Medline

Wang H, Kunkel DD, Schwartzkroin PA, Tempel BL (1994) Localization of $\mathrm{K}_{\mathrm{v}} 1.1$ and $\mathrm{K}_{\mathrm{v}} 1.2$, two $\mathrm{K}$ channel proteins, to synaptic terminals, somata, and dendrites in the mouse brain. J Neurosci 14:4588-4599. Medline

Winklhofer M, Matthias K, Seifert G, Stocker M, Sewing S, Herget T, Steinhäuser C, Saaler-Reinhardt S (2003) Analysis of phosphorylation-dependent modulation of Kv1.1 potassium channels. Neuropharmacology 44:829-842. CrossRef Medline

Xu B, Ionita-Laza I, Roos JL, Boone B, Woodrick S, Sun Y, Levy S, Gogos JA, Karayiorgou M (2012) De novo gene mutations highlight patterns of genetic and neural complexity in schizophrenia. Nat Genet 44:1365-1369. CrossRef Medline

Yamada J, Saitow F, Satake S, Kiyohara T, Konishi S (1999) GABA(B) receptor-mediated presynaptic inhibition of glutamatergic and GABAergic transmission in the basolateral amygdala. Neuropharmacology 38: 1743-1753. CrossRef Medline

Zhang CL, Messing A, Chiu SY (1999) Specific alteration of spontaneous GABAergic inhibition in cerebellar purkinje cells in mice lacking the potassium channel $\mathrm{K}_{\mathrm{v}} 1.1$. J Neurosci 19:2852-2864. Medline

Zhang HT, Huang Y, Masood A, Stolinski LR, Li Y, Zhang L, Dlaboga D, Jin SL, Conti M, O'Donnell JM (2008) Anxiogenic-like behavioral phenotype of mice deficient in phosphodiesterase 4B (PDE4B). Neuropsychopharmacology 33:1611-1623. CrossRef Medline

Zhao Y, Zhang HT, O'Donnell JM (2003) Antidepressant-induced increase in high-affinity rolipram binding sites in rat brain: dependence on noradrenergic and serotonergic function. J Pharmacol Exp Ther 307:246253. CrossRef Medline

Zhou FM, Hablitz JJ (1996) Layer I neurons of rat neocortex. I. Action potential and repetitive firing properties. J Neurophysiol 76:651-667. Medline

Zhou L, Messing A, Chiu SY (1999) Determinants of excitability at transition zones in $\mathrm{K}_{\mathrm{v}} 1.1$-deficient myelinated nerves. J Neurosci 19:57685781. Medline

Zucker RS, Regehr WG (2002) Short-term synaptic plasticity. Annu Rev Physiol 64:355-405. CrossRef Medline 